\title{
Okullarda Öğrenme İklimi Ölçeği’nin (OÖİÖ) Geliştirilmesi: Geçerlik ve Güvenirlik
}

\section{Çalışması*}

\author{
Gökhan SAVAŞ ${ }^{* *}$, Nihan DEMİRKASIMOĞLU****
}

- Geliş Tarihi: 17.08.2020 • Kabul Tarihi: 08.11.2020 • Çevrimiçi Yayın Tarihi: 01.12.2020

\section{$\ddot{\mathbf{O} z}$}

Okullarda öğrenmeyi destekleyici bir iklim oluşturulması, öğretmenin mesleki performansının geliştirmesi yoluyla öğrenci başarısının artırılmasında önemli bir belirleyici olarak görülmektedir. $\mathrm{Bu}$ araştırmanın amacı, öğretmenlerin okullarında öğrenme iklimine yönelik algılarını ölçmeye yönelik geçerli ve güvenilir bir ölçme aracı geliştirmektir. Araştırma kapsamında alanyazından ve öğretmenlerle yapılan görüşmelerden faydalanılarak madde havuzu oluşturulmuş ve kapsam geçerliği için uzman görüşüne başvurulmuştur. Araştırmanın verileri 2020 yılının bahar döneminde resmi 18 ilkokul, 20 ortaokul ve 15 lisede görev yapan gönüllü 589 öğretmenden oluşan iki farklı çalışma grubundan toplanmıştır. Verilerin çözümlenmesinde madde analizi, açımlayıcı faktör analizi, birinci ve ikinci düzey doğrulayıcı faktör analizi yapılmış ve güvenirlik katsayıları hesaplanmıştır. Madde analizi ve AFA sonucunda toplam 22 madde ve dört alt boyuttan oluşan bir ölçek elde edilmiştir. Ortaya çıkan alt boyutlar işbirlikçi ortam, okul müdürü desteği, okul imkânları ve mesleki ilgi olarak adlandırılmıştır. DFA sonucunda elde edilen bulgular ölçeğin kabul edilebilir bir uyuma sahip olduğunu göstermiştir. Ölçeğin güvenirliği için .93 olarak hesaplanan Cronbach Alfa iç tutarlık katsayıs1 ölçeğin oldukça güvenilir olduğunu ortaya koymuştur. Bu bulgulara göre, Okullarda Öğrenme İklimi Ölçeği’nin öğretmenlerin öğrenme iklimine yönelik algılarını ölçmek amacıyla kullanılabilecek geçerli ve güvenilir bir ölçme aracı olduğu söylenebilir. Gelecek çalışmalarda ölçeğin özel okul öğretmenleri üzerinde geçerlik ve güvenirlik çalışmalarının yinelenmesi önerilebilir.

Anahtar sözcükler: okul iklimi, öğrenme iklimi, okullarda öğrenme iklimi

Atıf:

Savaş, G. ve Demirkasımoğlu, N. (2021). Okullarda öğrenme iklimi ölçeği’nin (oöiö) geliştirilmesi: geçerlik ve güvenirlik çalışması. Pamukkale Üniversitesi Eğitim Fakültesi Dergisi, 52, 147178. doi:10.9779.pauefd. 781446

\footnotetext{
* Bu çalışma 1. yazarın doktora tezinden üretilmiştir.

** Öğretmen, Milli Eğitim Bakanlığı, ORCID ID: 0000-0003-0690-8733, gokhansavas37@ gmail.com

*** Doç. Dr., Hacettepe Üniversitesi Eğitim Yönetimi Bölümü, ORCID ID: 0000-0001-8609-9985, nihansal@ yahoo.com
} 


\section{Giriș}

Hızla değişen, karmaşıklaşan ve çeşitlenen iş çevrelerinde, çalışanların yeni koşullara uyum sağlayabilmesi için yeterliklerini sürekli güncellemesi gerekmektedir. Nikolova ve diğerlerine göre (2014), örgütlerin varlıklarını sürdürebilmeleri, çalışanları için öğrenmeye teşvik edici ortamlar sağlamalarına bağlıdır. Çalışanlarına bilgi ve becerilerini geliştirebilecekleri ve meslektaşlarıyla paylaşabilecekleri öğrenme ortamları sunmak örgütlerin amaçlarına ulaşmasında etkili bir yol olarak görülmektedir (Marsick ve Watkins, 2003). Öğrenmeyi destekleme, yaratıcılık, yenilikçilik ve yönetim uygulamaları gibi iş ortamına ilişkin özellikler çalışanların öğrenmeye ilişkin inanç ve tutumlarını önemli ölçüde etkilemektedir (Bates ve Khasawneh, 2005). Motivasyon ve öğrenme becerileri gibi faktörlerin yanı sıra çalışanların iş ortamına ilişkin algıları da öğrenmeleri üzerinde oldukça etkilidir (Atwal, 2013). İş ortamına yönelik bu algıların "iklim” çatısı altında incelendiği ve bireylerin yaratıcılık, öğrenme ve performansları üzerinde belirleyici olduğu öne sürülmektedir (Hetland vd., 2011; Rousseau, 1988). Bu nedenle, örgütlerde öğrenmenin etkili bir biçimde gerçekleşmesi için olumlu bir öğrenme ikliminin oluşturulması gereklidir.

Alanyazında örgütlerdeki öğrenme koşullarına işaret etmek için “öğrenme iklimi” (Atwal, 2013; Bowen ve Kilmann, 1975; Bozdoğan ve Sağnak 2011; Cherkowski, 2016; Eldor ve Harpaz, 2016; Hallinger, Bickman ve Davis, 1996; O’Donnell ve White, 2005; Shoshani ve Eldor, 2016; Yielding, 1993), “öğrenme kültürü” (Bates ve Khasawneh, 2005; Koops ve Winsor, 2006; Masitsa, 2005; Oluremi, 2008), “akademik iklim” (Wang ve Degol, 2016), “öğrenme yönelimi” (Opfer, Pedder ve Lavicza, 2011), “öğrenme atmosferi” (Pan, 2004) ve öğrenme ortamı (Stoll, 2009) gibi kavramların kullanıldığı görülmektedir. Kültür bireylerin örgüt hakkındaki inanç ve değerleri gibi daha soyut kavramları yansıtırken, iklim çalışma ortamının bireysel algılara dayalı, daha gözlemlenebilir ve ölçülebilir özelliklerini içermektedir (Schein, 1990; Wang 2012). İklim, bireylerin davranışlarını etkileyen örgütsel ortama yönelik bireysel beklentileri, algıları ve yorumlarıdır (Denison, 1996). Okul iklimi ise öğretim ve öğrenmenin gerçekleştiği okul ortamıyla ilişkili bir kavram olup, okul yöneticisi ve öğretmenlerin görev yaptıkları okulun özellikleri hakkında hissettiklerini yansitmaktadır (Johnson ve Johnson, 1999; Kaplan ve Geoffroy, 1990). Bu nedenle, mevcut araştırmada okulun öğrenmeye ilişkin daha somut ve gözlemlenebilir özelliklerini yansıtan “öğrenme iklimi” kavramı kullanılmıştır. 
Son y1llarda öğrenme iklimi, öğretmen etkililiğini artıran önemli bir örgütsel faktör olarak yaygın bir biçimde kabul görmektedir (Eldor ve Harpaz, 2016). Ayrıca, örgütlerin öğrenmeyi destekleyen bir iklim oluşturması çalışanların mesleki gelişimini desteklemekte de önemli bir yol olarak görülmektedir (Nikolova vd., 2014). Alanyazında, okullarda öğrenme ikliminin öğretmenlerin mesleki öğrenmesi (Atwal, 2013; Opfer, Pedder ve Lavicza, 2011), öğrenme kapasitesi (Prieto ve Revilla, 2006), öğretmenlerin teknolojiyi kullanma istekleri (Vermeulen vd., 2017), iş doyumu ve motivasyon (Shoshani ve Eldor, 2016), yenilikçi davranışlar (Sung ve Choi, 2014) ve öğrenci öğrenmesi (Bowen ve Kilmann, 1975; Moreland 1984) gibi kavramlarla ilişkilendirildiği görülmektedir. Öğrenme iklimine ilişkin yapılan çalışmalar, örgütsel koşulların öğrenme üzerinde teşvik edici ya da engelleyici bir rol oynayabileceğini ortaya koymuştur (Cortini, 2016; Nikolova vd., 2014). Öğretmen öğrenmesinin önemli bir unsuru olarak görülen öğrenme iklimi, okulda öğretmenlerin bilgiyi elde edebileceği, paylaşabileceği ve öğrenebileceği çeşitli imkân ve faaliyetlerden oluşan ortam olarak görülmektedir (Shoshani ve Eldor, 2016). Örgütsel bir faktör olarak öğrenme iklimi ise, öğretmenlerin formel ve informel mesleki öğrenme fırsatlarına ulaşmasında önemli rol oynamaktadır (Atwal, 2013). Olumlu bir öğrenme iklimine sahip olan okullarda, karşılaşılan sorunların çözümünde okulun tüm üyeleri birlikte hareket etmekte ve ortak bir hedef doğrultusunda sorumluluk almakta, öğretmenler kendilerini daha değerli hissetmekte ve öğrenme faaliyetlerine katılmada daha istekli davranmaktadırlar (Şişman, 2011). Olumlu bir öğrenme iklimi algısı, öğretmenlerde başarı ve memnuniyet hissi uyandırarak derslerinde yeni öğretim uygulamaları kullanmalarına ve deneyimlerini yansıtmalarına olumlu katkıda bulunmaktadır (Shoshani ve Eldor, 2016). Sonuç olarak, okullarda öğretmenlerin mesleki yeterliliklerinin geliştirilmesini kolaylaştıran olumlu bir öğrenme iklimi öğrenci başarısı için de önemli görülmektedir (Deal ve Peterson, 1999).

Öğretmen niteliğinin geliştirilmesi ve öğretmenlerin desteklendiği öğrenme ortamlarının oluşturulması hem öğrenci başarısının hem de öğretmenlerin mesleki performanslarının artırılmasında önemli rol oynadığından (Hodkinson ve Hodkinson, 2005; Shoshani ve Eldor, 2016), öğretmenlerin kapasitesini geliştirmek ve mesleki becerilerini artırmak son yıllarda eğitim politikalarının odak noktası olmuştur (Villegas-Reimers, 2003). Okulların normları, yapıları ve uygulamaları öğretmenlerin öğrenmesi için destekleyici veya engelleyici olabilmektedir. Sürekli öğrenme fırsatları sunan; araştırmayı, diyaloğu, iş birliği ve takım çalışmasını teşvik eden ve liderliğin paylaşıldığı bir sistemi oluşturan okullar 
öğretmenlerin mesleki öğrenmesine daha fazla katkı sağlamaktadır (Opfer, Pedder ve Lavicza, 2011). Etkileşime dayalı ve sürekli bir deneyim ve bilgi takası olan öğretmen mesleki öğrenmesinde sınıf ve okulun sosyal ortamı öğrenmenin asıl gerçekleştiği yerdir (Liu, Hallinger ve Feng, 2016). Öğretmen mesleki öğrenmesi etkili okullar öğretmenleri destekleyen ve mesleki gelişimi için olumlu bir öğrenme ortamı sağlayan okullardır (Schunk ve Pajares, 2009). Aksi söz konusu olduğunda, öğretmenler, öğrenmede ve öğrendiklerini öğretim uygulamalarına yansıtmada sorun yaşamaktadırlar (Hollingsworth, 1999).

Öğrenme iklimine ilişkin yeterli sayıda geçerli ve güvenilir ölçme aracının olmamasının bu konuda yapılacak çalışmalar için sınırlayıcı bir etken olduğu ifade edilmektedir (Nikolova vd., 2014). Türkiye bağlamında okullarda öğrenme iklimini ölçmeye yönelik farklı dil ve kültürlerden uyarlanan ölçeklerin kullanıldığı görülmektedir. Yapılan bazı çalışmalarda Tennessee Okul Güvenliği Merkezi ve Lincoln Okulları tarafindan geliştirilen “Öğrenme İklimi Ölçeği” kullanılmıştır (Bora, 2010; Çamur, 2006; Şentürk ve Mutlu, 2019). Bozdoğan (2010) tarafından çalışmada ise Hoyle (1972) tarafından geliştirilen “Okul Öğrenme Envanteri” Türkçeye uyarlanarak kullanılmıştır. Her ülkenin farklı bir eğitim sistemi ve kültürel yapısı olduğu göz önüne alındığında öğretmenlerin öğrenme iklimine ilişkin algılarını belirlemeye yönelik Türk dili ve kültürüne uygun bir biçimde geliştirilen geçerli ve güvenilir bir ölçme aracının gerekli olduğu düşünülmektedir.

İlgili alanyazın incelendiğinde okullarda öğrenme iklimine yönelik araştırmaların çoğunlukla öğrenci algılarını ölçmeye yönelik gerçekleştirildiği görülmektedir (Bama, 1999; Damico ve Roth, 1993; Gerold ve Barnes, 1986; Kanadlı ve Bağçeci, 2016; Strodl, 1988). Sosyal Bilişsel Kuram'a göre öğrenci ve öğretmenlerin okuldaki farklı rolleri okul ortamına ilişkin algılarında farklılaşmaya neden olmaktadır (Bandura, 1991). Okul ikliminin öğrenciler için daha az önemli olan unsurları öğretmenlerin okul iklimine ilişkin algılarını önemli ölçüde etkileyebilmektedir. Öğretmenlerin algıları da öğretime ilişkin aldıkları kararlarda belirleyici bir unsurdur (Perry ve Rahim, 2011). Bu bağlamda, öğretmenlerin okul iklimine ilişkin algılarını belirlemek amacıyla yeni ölçme araçlarının geliştirilmesi gerekli görülmektedir (Liu vd., 2014). Aynı zamanda, alanyazında eğitim örgütleri dışında öğrenme iklimini ölçmeye yarayan veri toplama araçları bulunsa da (Eldor ve Harpaz, 2016; Bates ve Khasawneh, 2005; Nikolova vd., 2014) okullarda öğrenme iklimini öğretmen görüşlerine göre ölçen ölçme araçları sınırlıdır (Shoshani ve Eldor, 2016). Ayrıca, mesleki öğrenme toplumu ölçeklerinin de öğretmen öğrenmesine yönelik okul yapısını belirlemek amacıyla kullanılmasına rağmen, bu ölçeklerin bazı boyutlarının Türk eğitim sistemine uygun 
olmadığı ve çalışmayacağı ifade edilerek eğitimin kültürel yapısı ve kodları dikkate alınarak yeni ölçme araçları geliştirilmesi önerilmektedir (Öğdem, 2015). Öğretmen öğrenmesini geliştirmek okullarda hâkim olan öğrenme ikliminin özelliklerinin belirlenmesini gerektirmektedir. Okullarda öğretmen öğrenmesine yönelik geliştirilen geçerli ve güvenilir bir ölçme aracının hem kuramsal olarak hem de uygulamada fayda sağlayacağı varsayılmaktadır. Mevcut araştırma kapsamında geliştirilen ölçme aracının okulların öğrenme iklimine ilişkin özelliklerinin belirlenmesini ve geliştirilmesini sağlayarak alanyazına katkıda bulunacağı düşünülmektedir.

\section{Öğrenme İklimi}

Öğrenme iklimi etkili okullara ilişkin yapılan araştırmalar neticesinde ortaya çıkan, okul iklimi ve örgüt iklimi kavramlarından farklı olarak öğrenmeye odaklanan daha yeni bir kavramdır (Resendiz, 1994). Okulların yeniden yapılandırılması sürecinde öğrenen örgüt yaklaşımı öğrenme iklimi kavramının ortaya çıkmasında önemli bir faktör olmuştur (Çamur, 2016). Ayrıca öğrenme ikliminin örgütsel performansla olan ilişkisi de bu kavramın yaygın hale gelmesine katkıda bulunmuştur (Mikkelsen ve Grønhaug, 1999). Marsick ve Watkins (2003)'e göre öğrenme iklimi çalışanların bilgiyi üretme, elde etme ve aktarmalarına katkı sağlayan faydalı örgütsel etkinliklere yönelik algılarıdır. Lowe (1990) öğrenme iklimini bireylerin olumlu bir öğrenme ortamı sağlayan fiziksel ya da psikolojik değişkenlere ilişkin his ve algıları olarak tanımlamıştır. Honey ve Mumford'a göre (1996) öğrenme iklimi, mesleki gelişime yönelik davranış ve uygulamaların desteklendiği ortamdır. Nikolova ve diğerlerine (2014) göre öğrenme iklimi, çalışanların öğrenme davranışlarını geliştiren, ödüllendiren ve destekleyen örgütsel politika ve uygulamalara yönelik algılarıdır. Eldor ve Harpaz (2016) ise öğrenme iklimi kavramını çalışanların, örgütün öğrenmeyi teşvik etme derecesine ilişkin algıları olarak tanımlamıştır.

Lezotte ve diğerlerine (1980) göre öğrenme iklimi okullarda kendine özgü bir anlama sahiptir. "Okul” ve "öğrenme iklimi” terimlerinin bir araya getirilmesiyle okul ortamında süregelen öğrenme uygulamalarının oluşturduğu bir atmosfere dikkat çekilmektedir. Öğrenme ve öğretmeyi kolaylaştıran olumlu bir okul iklimi okullarda öğrenme kültürünün önemli bir parçasıdır. Olumlu bir öğrenme iklimine sahip olan okullarda öğretmenler meslektaşlarıyla ve okul yöneticileriyle iş birliği içinde çalışmakta, birbirlerine saygı ve güven duymaktadırlar (Ellis, 1988). Silins, Mulford ve Zarins (2002) olumlu öğrenme ortamı olan okullarda liderliğin paylaşıldığını, okul çalışanları arasında iş birliğinin 
desteklendiğini ve öğretmenlerin öğrenme ihtiyaçlarının karşılandığını belirtmiştir. Kaplan ve Geoffroy (1990) olumlu bir öğrenme ikliminin öğretmenlerin mesleki yeterlilik duygularını güçlendirerek daha fazla sorumluluk ve risk almalarına katkıda bulunduğunu öne sürmüştür. Öğretmenler destek gördükleri olumlu bir öğrenme ikliminde kendilerini daha güçlü hissetmekte, okulun amaçlarına bağl1lık göstermekte ve meslektaşlarına güvenmektedir (Liu ve diğerleri, 2014). Olumlu bir öğrenme iklimi öğretmenlerin öğretim süreçlerinde söz sahibi olmalarına, olumlu iletişim kurmalarına ve motivasyonlarının artmasına olanak sağlamaktadır (Yielding, 1993). Öğretmenler kendilerini destekleyen bir okul ikliminde öğrenci başarısı için daha fazla sorumluluk almakta, karşılaştıkları sorunlar karşısında pes etmemekte ve öğretim konusunda daha istekli davranmaktadırlar (Sweetland ve Hoy, 2000).

\section{Okullarda Öğrenme İkliminin Boyutları ve Ölçülmesi}

Okullarda öğrenme ikliminin ölçülmesine yönelik ilk çalışmalardan birisi Hoyle (1972) tarafından yapılan araştırmadır. Hoyle (1972) öğrenme iklimine yönelik okul çalışanlarının algılarını belirlemek amacıyla “Okul Öğrenme İklimi Envanteri” adlı bir ölçme aracı geliştirmiştir. Ölçekte öğrenme iklimine yönelik liderlik, özgürlük, değerlendirme, uyum ve iş birliği olmak üzere beş alt boyut belirlenmiştir. Moreland (1984) tarafindan okullarda öğrenme iklimine yönelik öğretmen algılarını ölçmek amacıyla yapılan çalışmada "Okul Öğrenme İklimini Değerlendirme Ölçeği” geliştirilmiştir. Bu çalışmada öğrenme iklimi öğretim liderliği, akademik vurgu, güvenli ortam, beklentiler ve materyal kullanımı olarak boyutlandırılmıştır. Bartram ve diğerleri (1993) tarafından yapılmış olan çalışma kapsamında geliştirilen “Öğrenme İklimi Ölçeği” yönetim tarzı, zaman, özgürlük ve sorumluluk, takım çalışması, gelişim fırsatları, yönlendirme ve memnuniyet olmak üzere yedi boyuttan oluşmuştur. Öğrenme iklimini belirlemek amacıyla kullanılan bir başka ölçme aracı da Marsick ve Watkins'in (2003) geliştirmiş olduğu “Öğrenen Örgüt Ölçeği”dir. Ölçek, okullarda öğrenme iklimini ölçmeye yönelik olarak da bazı çalışmalarda kullanılmıştır (Eldor ve Harpaz, 2016; Shoshani ve Eldor, 2016). Öğretmenlerin görev yaptıkları okulların sürekli öğrenme, araştırma, diyalog, takım halinde öğrenme, ortak vizyon ve stratejik liderlik özelliklerini değerlendirmelerine yönelik maddeler içeren bu ölçek tek boyutlu bir yapıdadır. Aldridge, Laugksch, ve Fraser (2006) öğretmenlerin okul ortamına yönelik algılarını ölçmek amacıyla geliştirdikleri “Okul Ortamı Ölçeği'nin” boyutlarını veli katılımı, öğrenci desteğgi, ilişki, profesyonel ilgi, özgürlük, yenilikçilik, kaynaklar, iş baskısı ve sonuca dayalı eğitim olarak ortaya koymuşlardır. Nikolova ve 
diğerleri (2014) ise örgütlerde çalışanların öğrenme iklimine yönelik algılarını belirlemek amacıyla kolaylaştırma iklimi, takdir iklimi ve hatadan kaçınma iklimi olarak üç boyuttan oluşan “Öğrenme İklimi Ölçeğini” geliştirmişlerdir. Alanyazında yaygın olarak kullanılan ölçme araçlarından bir diğeri de Tennessee Okul Güvenliği Merkezi ve Lincoln Okulları tarafından geliştirilen “Öğrenme İklimi Ölçeği'dir.” Bu ölçeğin boyutları ise olanaklar, güvenlik, yönetim süreçlerine katılma, okul kaynakları ve çevre, öğretim, öğrenci yönetimi, müfredat, başarı ve moral olarak belirlenmiştir (Çamur, 2006).

Alanyazında okullarda öğrenme ikliminin çeşitli boyutlarda ele alındığ1 görülmektedir. Ancak öğrenme iklimine ilişkin yapılan tanımlar ve geliştirilen ölçme araçlarının boyutları incelendiğinde bazı ortak noktaların bulunduğu görülmektedir. Bunlar liderlik (yönetici desteği), iş birliğgi, paylaşım, okul kaynakları, bireysel özellikler ve ortak vizyondur. Vurgulanan ortak noktalar, mevcut çalışma kapsamında etkili bir öğretmen öğrenmesi için gerekli olan öğrenme iklimine yönelik ölçme aracının geliştirilmesinde yol gösterici olmuştur. Geliştirilen ölçeğin boyutlarının alanyazında daha önce yapılan çalışmalarda ortaya konan boyutlarla tutarlı olmasına dikkat edilmiştir. Ayrıca öğrenme iklimine ilişkin daha önce geliştirilen ölçme araçlarının birçoğu yalnızca öğretmen algılarını ölçmeye yönelik geliştirilmediği için maddelerin yazılması sürecinde öğretmenlerle yapılan görüşmelerden de yararlanılmıştır.

\section{Yöntem}

Araştırma kapsamındaki veriler Hacettepe Üniversitesi Senatosu Etik Komisyonunun 09.06.2020 tarihli toplantısı 35853172-600 sayılı kararı gereğince toplanmıştır. Okullarda öğrenme ikliminin öğretmen görüşlerine göre değerlendirilmesine yönelik geçerli ve güvenilir bir ölçme aracı geliştirmenin amaçlandığı mevcut araştırma betimsel tarama modelindedir. Tarama modellerinde geçmişte ya da günümüzde mevcut olan bir durumun, olduğu şekliyle betimlenmesi amaçlanmaktadır (Karasar, 1999). Araştırmanın çalışma grubu ve veri toplama sürecine ilişkin bilgiler bu bölümde sunulmuştur.

\section{Çalışma Grubu}

Mevcut araştırma kapsamında verilerin toplanması için iki farklı çalışma grubuna ulaşılmıştır. Çalışma grupları, 2020 yılı bahar döneminde resmi ilkokul, ortaokul ve liselerde görevli gönüllü öğretmenlerden oluşmaktadır. Örneklemin belirlenmesinde kolay ulaşılabilir durum örneklemesi yöntemi tercih edilmiştir. Bu yöntem, ulaşılması kolay ve yakın bir durumu seçmesi yönünden araştırmacıya hız ve pratiklik sağlayan bir yöntemdir (Yıldırım 
ve Şimşek, 2008). 279 öğretmenin oluşturduğu birinci çalışma grubundan çevrimiçi yolla toplanan verilerle Açımlayıcı Faktör Analizi (AFA), 310 öğretmenden oluşan ikinci çalışma grubundan toplanan verilerle Doğrulayıcı Faktör Analizi (DFA) gerçekleştirilmiştir. Araştırmaya katılan öğretmenlere ilişkin demografik bilgiler Tablo 1'de verilmektedir.

Tablo 1. Çalışma Grubuna İlişkin Demografik Bilgiler

\begin{tabular}{|c|c|c|c|c|c|}
\hline \multicolumn{2}{|c|}{ Değişken } & \multicolumn{2}{|c|}{ Birinci Çalışma Grubu } & \multicolumn{2}{|c|}{ İkinci Çalışma Grubu } \\
\hline & & $f$ & $\%$ & $f$ & $\%$ \\
\hline \multirow[t]{2}{*}{ Cinsiyet } & Kadın & 166 & 59,5 & 174 & 56,1 \\
\hline & Erkek & 113 & 40,5 & 136 & 43,9 \\
\hline Okul & İlkokul & 101 & 36,2 & 115 & 37,1 \\
\hline \multirow[t]{2}{*}{ Kademesi } & Ortaokul & 100 & 35,8 & 150 & 48,4 \\
\hline & Lise & 78 & 28,0 & 45 & 14,5 \\
\hline Mesleki & $1-5$ y1l & 38 & 13,6 & 47 & 15,2 \\
\hline \multirow[t]{4}{*}{ Kidem } & $6-10$ y1l & 60 & 21,5 & 64 & 20,6 \\
\hline & $11-15$ y1l & 86 & 30,8 & 83 & 26,8 \\
\hline & $16-20 \mathrm{y} 1 \mathrm{l}$ & 49 & 17,6 & 61 & 19,7 \\
\hline & 20 yıl ve üzeri & 46 & 16,5 & 55 & 17,7 \\
\hline Eğitim & Lisans & 215 & 77,1 & 267 & 86,1 \\
\hline \multirow[t]{2}{*}{ Durumu } & Lisansüstü & 64 & 22,9 & 43 & 13,9 \\
\hline & Toplam & 279 & 100 & 310 & 100 \\
\hline
\end{tabular}

Tablo 1'e göre, AFA uygulanan birinci çalışma grubunda bulunan katılımcıların \%59.5'ini ( $\mathrm{n}=166)$ kadınlar, \%40.5'ini $(\mathrm{n}=113)$ erkekler oluşturmaktadır. Katılımcıların \%36.2'si (n=101) ilkokulda, \%35.8'i (n=100) ortaokulda ve \%28'i (n=78) lisede görev yapmaktadır. Katılımcilardan \%13.6's1 (n=38) 1-5 y1l, \%21.5'i (n=60) 6-10 y1l, \%30.8'i (n=86) 11-15 yıl, \%17.6'sı (n=49) 16-20 y1l, \%16.5'i (n=46) 21 yıl ve üzeri kıdeme sahiptir. Katılımcıların \%77.1’i (n=215) lisans, \%22.9’u (n=64) lisansüstü eğitimini tamamlamıştır. DFA uygulanan ikinci çalışma grubunda yer alan katılımcıların \%56.1'i $(n=174)$ kadın, \%43.9'u (n=136) erkeklerden oluşmaktadır. Katılımcıların \%37.1'i (n=115) ilkokulda, \%48.4'ü (n=150) ortaokulda ve \%14,5'i $(n=45)$ lisede görev yapmaktadır. Katılımcıların \%15.2'si (n=47) 1-5 y11, \%20.6's1 (n=64) 6-10 y11, \%26.8'i (n=83) 11-15 y11, \%19.7'si (n=61) 16-20 y11, \%17.7'si (n=55) 21 yıl ve üzeri kıdeme sahiptir. Katılımcıların \%86.1'i (n=267) lisans, \%13.9’u (n=43) lisansüstü programlardan mezun olmuştur. 
Faktör analizinin sağlıklı bir biçimde yapılabilmesi için yeterli örneklem büyüklüğünün sağlanması gerekmektedir (Tabachnik ve Fidell, 2007). Alanyazında faktör analizi için gereken örneklem büyüklüğü hakkında farklı görüşler yer almaktadır. Örneğin Kline (1994) faktör analizi için gereken katılımcı sayısının en az 100 olduğunu ancak daha büyük örneklemlerin daha sağlıklı sonuçlar vereceğini belirtmiştir. Comrey ve Lee (1992) faktör analizi için 200 katılımcının yeterli olduğunu öne sürmüştür. Cattell (1978) ölçekte yer alan madde sayısının 3 ile 6 katı büyüklüğünde ya da 200-250 civarında bir örneklem büyüklügünün genellikle yeterli olduğunu ifade etmiştir. Tavşancıl (2006) ise ölçekte bulunan madde sayısının en az beş katı kadar katılımcının faktör analizi için gerekli olduğunu belirtmiştir. Alanyazında belirtilen ölçütler dikkate alındığında faktör analizi için gereken örneklem büyüklüğüne ulaşıldığı söylenebilir.

\section{Veri Toplama Aracının Geliştirilmesi}

Ölçek maddelerinin belirlenmesinde tümdengelimci ve tümevarımcı yöntemler bir arada kullanılmıştır. Tümdengelimci yaklaşımda ölçek maddeleri ilgili alanyazının kapsamlı bir biçimde taranması sonucu oluşturulmaktadır. Tümevarımcı yaklaşımda ise araştırmacı ölçeğin uygulanacağ hedef kitle içinden belirlenen bir grupla yaptıkları görüşmeler sonucu ölçek maddelerini belirlemektedir (Hinkin, 1995). Bu bağlamda, mevcut araştırma kapsamında alanyazında öğrenme iklimine ilişkin çalışmalar detaylı bir biçimde taranmıştır. Ayrıca öğrenme iklimi konusunda daha önceden geliştirilen ölçekler incelenmiştir (Bartram vd., 1993; Hoyle, 1972; Nikolova ve diğerleri 2014; Opfer, Pedder ve Lavicza, 2011). Bunlara ek olarak, öğrenme iklimine ilişkin görüşlerini değerlendirmek amaciyla dördü ilkokul, beşi ortaokul ve üçü lisede görev yapan toplam 12 öğretmenin katılımıyla görüşmeler yapılmıştır. Yapılan alanyazın taraması ve görüşmeler sonucunda 35 maddelik bir madde havuzu oluşturulmuştur. Ölçek maddelerinin alanyazına dayalı olarak okul müdürü desteği, işbirlikçi ortam, okul imkânları, ve mesleki ilgi olmak üzere dört boyut altında yer alması düşünülmüştür. Örneğin, okul müdürü desteği boyutunda “Okul müdürü öğretmenleri yeni şeyler öğrenmeye teşvik eder”, işbirlikçi ortam boyutu altında "Öğretmenler mesleki bilgi ve deneyimlerini birbirleriyle paylaşır” okul imkânları boyutu altında “Öğretmenler mesleki öğrenmeleri için gerekli kaynaklara (kitap, dergi, internet vb.) sahiptir" ve mesleki ilgi boyutunda "Öğretmenler alanındaki güncel gelişmeleri takip eder" şeklinde maddelere yer verilmiştir. Ölçekte yer alan ifadelerin yanıtlanmasında Hiçbir zaman (1) ve Her Zaman (5) arasında sıralanan beşli Likert tipi bir derecelendirme kullanılmıştır. 
Ölçek maddelerinin ölçülmesi amaçlanan davranışları yansıtmada yeterli olmaları gerekmektedir. $\mathrm{Bu}$ doğrultuda, uzman görüşüne başvurmak ölçme aracının kapsam geçerliğini incelemede kullanılan yöntemlerden birisidir (Büyüköztürk vd., 2016). Birden fazla boyuttan oluşan ölçme araçlarında her bir boyutta yer alan maddelerin o boyuta ilişkin davranışla ilgili olup olmadığının belirlenmesinde uzman görüşlerinden yararlanılması gerekir (DeVellis, 2003). Bu bağlamda, ölçeğin kapsam geçerliğini sağlamak için 12'si Eğitim Yönetimi ve 1'i Ölçme ve Değerlendirme alanlarından olmak üzere 13 alan uzmanının görüşüne başvurulmuştur. Uzmanların her bir madde hakkındaki görüşleri "uygun", "kısmen uygun" ve "uygun değil" şeklinde hazırlanan bir form aracılığıyla alınmıştır. Katılımcıların uygun bulmadıkları ya da kısmen uygun buldukları maddeye ilişkin görüşlerini yazmaları istenmiştir. Uzman görüşlerinin değerlendirilmesi Lawshe tekniği kullanılarak yapılmıştır. Lawshe tekniğinde en az beş en fazla 40 uzmanın görüşüne ihtiyaç vardır. Uzmanların ölçekte yer alan maddeler hakkındaki görüşleri toplanarak kapsam geçerlik oranları (KGO) hesaplanmaktadır. 13 uzman için hesaplanan minimum KGO değeri .54'tür (Yurdugül, 2005). Bu bağlamda, mevcut araştırmada her bir madde için KGO değerleri hesaplanmıştır. KGO değeri .54'ün altında kalan dokuz madde formdan çıkarılmıştır. Ayrıca gelen öneriler doğrultusunda sekiz maddenin ifade ediliş biçimlerinde değişiklik yapılmıştır. Ölçek maddelerinin dil açısından uygunluğunu değerlendirmek için iki Türk dili uzmanından görüş alınmıştır. Uzmanların ölçekte yer alan maddelerin yazım kuralları, ifade ve noktalama işaretleri kullanımı açısından yaptıkları değerlendirmeler sonucunda ölçek maddeleri yeniden gözden geçirilmiştir. Ölçekte yer alan maddelerin anlaşılabilirliğine ilişkin örneklem grubu dışında 10 öğretmenin görüşüne başvurulmuştur. Alınan görüşler doğrultusunda 26 maddelik ölçek uygulama için hazır hale getirilmiştir.

\section{Verilerin Analizi}

Verilerin analizinde SPSS 20 ve AMOS 23 paket programları kullanılmıştır. Araştırma kapsamında elde edilen verilerin faktör analizine hazır hale getirilmesi amacıyla Z puanları ve Mahalanobis uzaklık değeri hesaplanmıştır. Verilerin ölçülmesi amaçlanan tutumla ilişkili olup olmadığını ve farklı dereceleri birbirinden ayırt edebilme özelliklerini incelemek amacıyla madde analizi yapılmıştır (Tezbaşaran, 2008). Verilerin normal dağılımını belirlemek üzere çarpıklık ve basıklık değerleri incelenmiştir. Ölçek maddeleri arasında çoklu bağlantı olup olmadığı maddeler arasındaki korelasyon değerleri $(r<.90)$ hesaplanarak belirlenmiştir (Tabachnick ve Fidell, 2007). Maddelerin ayırt edicilikleri, \% 27'lik alt ve üst grup ortalamaları karşılaştırılarak ve madde toplam korelasyonu 
hesaplanarak değerlendirilmiştir. Ölçme aracının yapı geçerliğini belirlemek amacıyla açımlayıcı faktör analizi (AFA) yapılmıştır. Değişkenler arasındaki ilişkilerin yapısından hareketle faktör belirlemeye yönelik yapılan bir analiz olan AFA, ölçek geliştirme çalışmalarında sıklıkla kullanılmaktadır (Büyüköztürk, 2012; Field, 2013). Faktör çıkarma yöntemi olarak Temel Bileşenler Analizinin (TBA) kullanılmasına karar verilmiştir çünkü TBA'nın diğer yöntemlere göre faktör belirsizliğini azaltmada daha etkili ve psikometrik olarak daha güçlü bir yöntem olduğu belirtilmektedir (Tabachnick ve Fidell, 2007). Ölçek faktörleri arasında ilişki olabileceği varsayıldığından eğik döndürme yöntemlerinden Direct Oblimin kullanılmıştır (Çokluk, Şekercioğlu ve Büyüköztürk, 2010). AFA'dan önce, elde edilen verilerin faktör analizine uygunluğu Kaiser-Meyer Olkin (KMO) değeri ve Bartlett küresellik testi ile belirlenmiştir. Faktör yapısı özdeğerlerin 1'den büyük olma ölçütü ve yamaç-birikinti grafiği dikkate alınarak belirlenmiştir. Yapılan AFA sonucunda, dört faktörden oluşan yapının doğruluğunu sınamak için birinci düzey ve ikinci düzey doğrulayıcı faktör analizi (DFA) gerçekleştirilmiştir. DFA, değişkenler arasında daha önceden belirlenen bir ilişkiye yönelik yapı ya da hipotezin test edilmesi için yapılan bir faktör analizi yöntemidir (Field, 2013). Modelin geçerliliği uyum iyiliği indeksleri; Ki-Kare Uyum Testi ( 2 2), İyilik Uyum İndeksi (GFI), Düzeltilmiş İyilik Uyum İndeksi (AGFI), Yaklaşık Hataların Ortalama Karekökü (RMSEA), Hata Kareleri Ortalama Karekökü (RMR), Karşılaştırmalı Uyum İndeksi (CFI) ve Normlaştııılmış Uyum İndeksi (NFI) hesaplanarak belirlenmiştir. Ölçeğin iç güvenirliğini belirlemek için Cronbach alfa iç tutarlılık katsayısı ve faktörler arasındaki korelasyon değerleri hesaplanmıştır.

\section{Bulgular}

$\mathrm{Bu}$ bölümde madde analizi, AFA, birinci ve ikinci düzey DFA ve güvenirlik analizleri sonucunda elde edilen bulgular yer almaktadır.

\section{Madde Analizi}

Okullarda Öğrenme İklimi Ölçeği’nde (OÖİÖ) yer alan maddelerin, ölçülmek istenen tutumla ilişkisi olup olmadığının ve ayırt edebilme özelliklerinin incelenmesi amacıyla yapılan madde analizi sonuçlarının verildiği Tablo 2 incelendiğinde, ölçekte yer alan maddelerin aritmetik ortalamalarının 2.78 ile 3.96 arasında olduğu görülmektedir. 
Tablo 2. Madde Analizi Sonuçları

\begin{tabular}{|c|c|c|c|c|c|c|c|}
\hline \multirow{4}{*}{$\begin{array}{l}\text { Madde } \\
\text { No }\end{array}$} & \multirow[t]{4}{*}{ Ort. } & \multirow[t]{4}{*}{ S.S. } & \multirow[t]{4}{*}{ Çarpıklık } & \multirow[t]{4}{*}{ Basıklık } & \multirow{2}{*}{\multicolumn{2}{|c|}{$\begin{array}{c}\text { Düzeltilmiş } \\
\text { Madde-Toplam }\end{array}$}} & \multirow{4}{*}{$\begin{array}{c}\text { Alt-Üst \%27 } \\
\text { Madde Ayırt } \\
\text { Edicilik İndeksi }\end{array}$} \\
\hline & & & & & & & \\
\hline & & & & & \multicolumn{2}{|c|}{ Korelasyonu $^{1}$} & \\
\hline & & & & & 1.düzey & 2.düzey & \\
\hline 1 & 3,50 & 1,134 &,- 421 &,- 701 & ,577 & ,592 & $12,267^{* * *}$ \\
\hline 2 & 3,50 & 1,166 &,- 444 &,- 650 & 683 & ,696 & $14,607^{* * *}$ \\
\hline 3 & 3,76 & 1,148 &,- 647 &,- 539 & 659 & ,670 & $15,136^{* * *}$ \\
\hline 4 & 3,75 & 1,046 &,- 583 &,- 247 & ,617 & ,626 & $14,254^{* * * *}$ \\
\hline 5 & 3,28 & 1,083 &,- 370 &,- 335 & ,639 & ,653 & $14,314^{* * *}$ \\
\hline 6 & 3,88 & 1,073 &,- 830 & ,037 & ,625 & ,626 & $13,932^{* * *}$ \\
\hline 7 & 3,86 & 1,095 &,- 778 &,- 158 & ,627 & ,633 & $14,540^{* * *}$ \\
\hline 8 & 3,80 & ,916 &,- 177 &,- 908 & ,562 &, 547 & $10,650^{* * *}$ \\
\hline 9 & 3,72 & ,843 &,- 238 &,- 508 & ,572 &, 560 & $10,841^{* * * *}$ \\
\hline 10 & 2,78 & ,951 &, 248 &,- 217 & ,236 & & $3,296^{* * *}$ \\
\hline 11 & 3,37 & ,942 & ,016 &,- 495 & ,488 & ,480 & $8,683^{* * *}$ \\
\hline 12 & 3,96 & ,843 &,- 911 & 1,293 &, 533 & & $8,717^{* * *}$ \\
\hline 13 & 3,60 & ,883 &,- 045 &,- 723 & ,616 & ,604 & $10,505^{* * * *}$ \\
\hline 14 & 3,30 & ,829 &,- 124 &,- 233 & ,546 & ,540 & $8,063^{* * *}$ \\
\hline 15 & 3,70 & ,931 &,- 472 &,- 236 & ,647 & ,640 & $13,663^{* * * *}$ \\
\hline 16 & 3,81 & ,872 &,- 366 &,- 354 & ,568 &, 554 & $11,573^{* * * *}$ \\
\hline 17 & 3,53 & ,940 &,- 246 &,- 398 & ,689 & ,676 & $15,889^{* * * *}$ \\
\hline 18 & 3,76 & ,878 &,- 290 &,- 598 & 699 & ,692 & $14,765^{* * *}$ \\
\hline 19 & 3,81 & ,846 &,- 381 &,- 211 & ,670 & ,654 & $12,164^{* * *}$ \\
\hline 20 & 3,57 & ,853 &,- 459 &, 030 & ,615 & ,615 & $11,260^{* * *}$ \\
\hline 21 & 3,12 & ,995 &, 025 &,- 553 &, 562 &, 564 & $9,892^{* * *}$ \\
\hline 22 & 3,96 & ,786 &,- 564 & ,129 & ,556 &, 554 & $9,157^{* * *}$ \\
\hline 23 & 3,86 & ,932 &,- 657 &, 027 &, 537 &, 538 & $9,245^{* * *}$ \\
\hline 24 & 3,43 & 1,100 &,- 246 &,- 732 &, 504 &, 502 & $9,390^{* * * *}$ \\
\hline 25 & 3,49 & 1,000 &,- 508 &,- 269 &, 519 &, 529 & $9,486^{* * *}$ \\
\hline 26 & 3,40 & 1,201 &,- 303 &,- 953 & ,459 & ,471 & $9,461^{* * *}$ \\
\hline
\end{tabular}


Tablo 2'de maddelerin çarpıklık ve basıklık değerleri incelendiğinde ise 12. maddenin tekli normallik varsayımını karşılamadığı görülmektedir. Çarpıklık ve basıklık katsayısının \pm 1 arasında olması verilerin normallikten önemli bir sapma göstermediğini ortaya koymaktadır (Çokluk, Şekercioğlu ve Büyüköztürk, 2010). Ölçek geliştirme aşamasında bu değerlerin dışında kalan maddelerin ölçekten çıkarılabileceği ifade edilmektedir (Şencan, 2005). Bu doğrultuda normal dağılım göstermediği belirlenen 12 . madde ölçekten çıkarılmıştır. Geriye kalan maddelerin çarpıklık ve basıklık katsayılarının .037 ile -.953 arasında değiştiği görülmüştür. Bu değerler verilerin normal dağılım gösterdiğini ortaya koymaktadır.

Yüksek ve pozitif madde toplam korelasyonu değerleri, bir ölçekte bulunan maddelerin birbirine yakın davranışları örneklediğini ve testin iç tutarlılığının yüksek olduğunu göstermektedir. Likert tipi ölçeklerde ölçek puanı ile düşük ilişki gösteren maddelerin ölçekten çıkarılması önerilmektedir (Tezbaşaran, 2008). Madde toplam korelasyonu değeri .30'un üzerinde olan maddelerin ayırt ediciliğinin iyi olduğu ifade edilmektedir (Büyüköztürk, 2012). Bu doğrultuda, madde toplam korelasyonu .30' dan düşük olan 10. madde de ölçekten çıkarılmıştır. Maddeler çıkarıldıktan sonra analiz tekrarlanmış ve maddelerin .47 ile .69 arasında sıralanan korelasyon değerleri aldığ görülmüştür. Son olarak \%27'lik alt ve üst grupların puanlarındaki farklara yönelik t değerlerinin 8.06 ile 15.89 arasında değiştiği ve $\mathrm{p}<.05$ düzeyinde anlamlı bir biçimde farklılaştığı sonucuna ulaşılmıştır. Bu bulgulara göre ölçekte bulunan maddelerin her birinin ayırt edici olduğu söylenebilir.

\section{Açımlayıcı Faktör Analizi}

Mevcut araştırma kapsamında elde edilen verilerin faktör analizine uygunluğunu değerlendirmek amaciyla öncelikle Kaiser-Meyer Olkin (KMO) ve Bartlett değerleri hesaplanmıştır. Yapılan işlem sonucunda KMO değeri .93 olarak bulunmuştur. Bartlett Küresellik testi (Ki Kare $=4502,72 ;$ sd $=276$; $\mathrm{p}<$,05) anlamlı sonuç vermiştir. KMO değerinin .60'ın üzerinde olması ve Bartlett Küresellik testi sonucunun anlamlı olması verilerin faktör analizine uygun olduğuna işaret etmektedir (Büyüköztürk, 2012; Field, 2013). Bu bulgular, araştırma verilerinin faktör analizi için uygun olduğunu ortaya koymuştur. 
AFA'da faktörleştirme tekniklerinden Temel Bileşenler Analizi kullanılmıştır. Yapılan analiz sonucunda ölçekte bulunan maddelerin özdeğeri 1 'in üzerinde olan dört faktör altında toplandığı görülmüştür. Ölçeğin faktör yapısını ortaya koyan bilgiler Tablo 3 'te verilmiştir.

Tablo 3. Temel Bileşenler Analizi Sonucunda Ölçeğin Faktör Yapısını Gösteren Bulgular

\begin{tabular}{lccc} 
Faktör & Özdeğer & Varyans $(\%)$ & Toplam Varyans (\%) \\
\hline 1 & 9,760 & 40,67 & 40,67 \\
2 & 3,342 & 13,93 & 54,60 \\
3 & 1,749 & 7,29 & 61,88 \\
4 & 1,262 & 5,26 & 67,14 \\
\hline
\end{tabular}

Faktör sayısının belirlenmesinde özdeğer, açıklanan varyans oranı ve yamaç-birikinti grafiği önemli göstergelerdir (Büyüköztürk, 2012; Çokluk, Şekercioğlu ve Büyüköztürk, 2010). Tablo 3 incelendiğinde birinci boyutun 9.760, ikinci boyutun 3.342, üçüncü boyutun 1.749 dördüncü boyutun 1.262 özdeğere sahip olduğu görülmektedir. Faktör analizinde özdeğeri 1 ve 1'in üzerinde olan faktörler, önemli faktörler olarak görülmektedir (Field, 2013). Mevcut bulgu, ölçeğin özdeğeri 1'den büyük olan dört boyuttan oluşabileceğini göstermiştir.

Açıklanan varyansa ilişkin bulgulara göre, birinci boyut toplam varyansın \%40,67'sini, ikinci boyut \%13,93'ünü, üçüncü boyut \% 7,29'unu, dördüncü boyut 5,26'sını açıklamaktadır. Tüm boyutlar ise ölçekteki toplam varyansın \%67,14'ünü açıklamaktadır. Toplam varyansın 2/3'ünün açıklandığı ilk faktör sayısı önemli faktör sayısı olarak kabul görmektedir. Açıklanan varyansın yüksek değer alması ilgili yapının o derece iyi ölçüldüğünü göstermektedir (Büyüköztürk, 2012). Bu bulgu OÖİÖ’nün toplam varyansının yeterli olduğu şeklinde yorumlanabilir. Ölçeğin faktör yapısına karar vermede kullanılan önemli göstergelerden bir diğeri olan yamaç-birikinti grafiğgi Şekil 1'de sunulmuştur.

Yamaç birikinti grafiğginde eğimin azaldığı noktaya kadar olan her bir noktanın arası faktör sayısı hakkında bilgi vermektedir. Eğimin azaldığı nokta kırılma noktasıdır ve buradan itibaren faktörlerin varyansa yaptığı katkı azalmaktadır (Çokluk, Şekercioğlu ve Büyüköztürk, 2010). Şekil 1 incelendiğinde dördüncü faktörden sonra çizginin eğiminde bir azalma olduğu ve grafiğgin yatay bir görünüm sergilediği görülmektedir. Bu nedenle, yamaç birikinti grafiği verilerine göre ölçeğin dört faktörden oluşan bir yapıya sahip olduğu ifade edilebilir. 


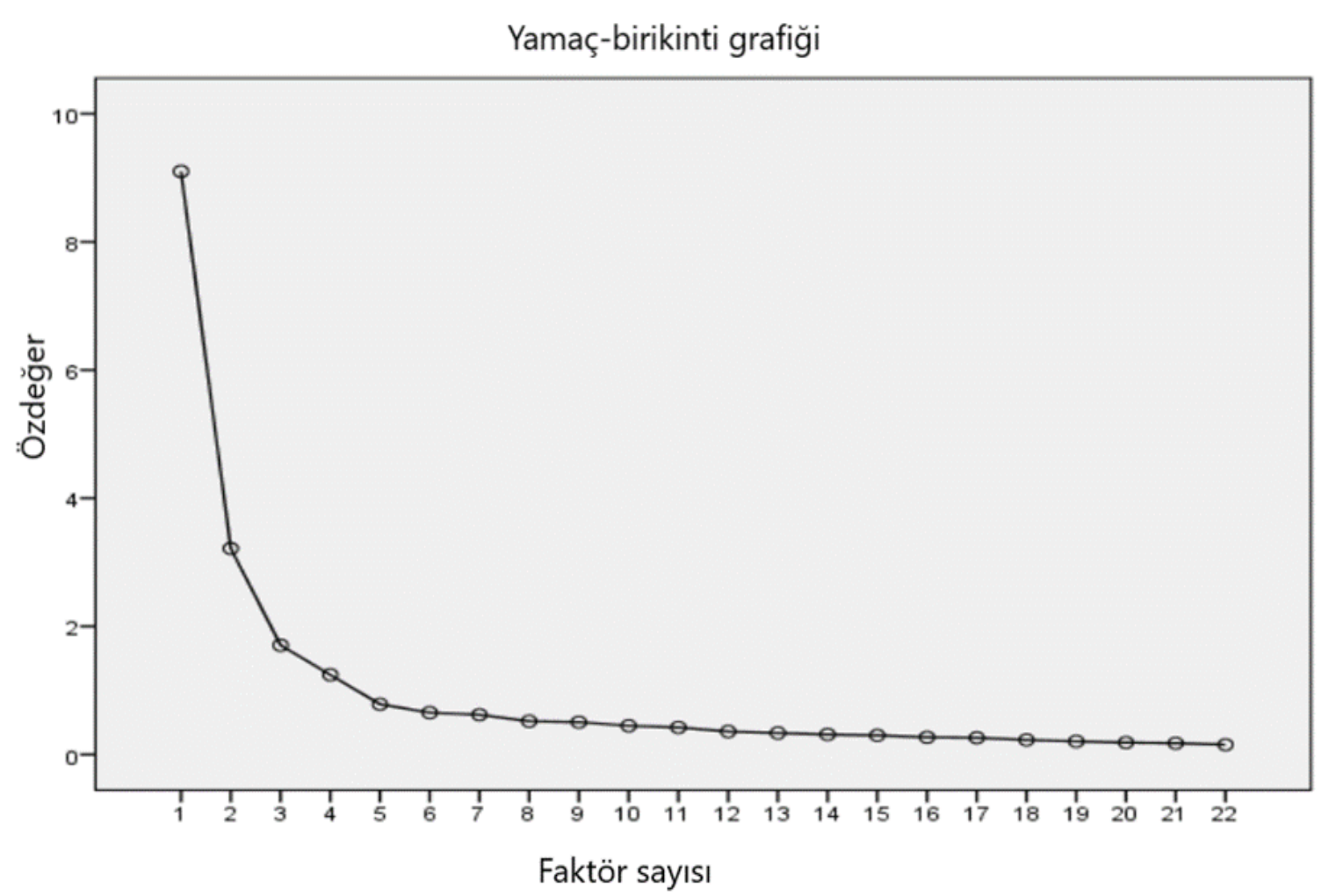

Şekil 1. Yamaç-Birikinti Grafiği

Ölçekte bulunan maddelerin hangi alt boyutlar altında yer aldığını belirlemek için faktörlerin birbirleriyle ilişkili olduğu gerekçesiyle eğik döndürme yöntemlerinden Direct Oblimin kullanılmıştır (Field, 2013). AFA sonucunda ölçekte bulunan maddelerin faktör yükleri ve ortak faktör varyansları Tablo 4'te verilmektedir.

Ölçeğin yapı geçerliğinin sağlanması için madde faktör yüklerinin .50'nin üzerinde olması gerektiği ifade edilmektedir (Fornell ve Larcker, 1981; Nunally, 1978). Bu nedenle faktör yük değerinin alt sınırı .50 olarak belirlenmiştir. Yapılan analiz sonucunda bazı maddelere ait faktör yük değerlerinin .50 'den küçük olduğu saptanmıştır. Bu nedenle 14. ve 21. maddeler ölçekten tek tek çıkarılarak analiz tekrarlanmıştır. Ölçekte birden fazla faktör altında yüksek yük değeri gösteren binişik maddeye rastlanmamıştır. Madde faktör yüklerinin yanı sıra ortak faktör varyansı değerleri de AFA sonucunda elde edilen bulguların değerlendirilmesinde kullanılmaktadır. Ortak faktör varyansı, çıkarılan faktörlerin birlikte temsil edilme derecesini göstermektedir. Bu nedenle ortak faktör varyansı. 20'nin altında olan maddelerin ölçekten çıkarılması önerilmektedir (Şencan, 2005). Analiz sonucunda. 20 altında ortak faktör varyansı değeri gösteren madde bulunmamıştır. 
Tablo 4. Açımlayıcı Faktör Analizine İlişkin Bulgular

\begin{tabular}{|c|c|c|c|c|c|c|c|}
\hline Madde No & 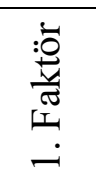 & 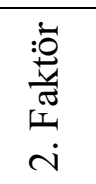 & 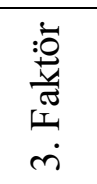 & $\begin{array}{l}: \overrightarrow{0} \\
\frac{\Delta}{\pi} \\
\frac{\pi}{\pi} \\
\dot{\forall}\end{array}$ & & 䒺 & 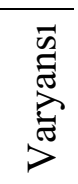 \\
\hline Madde 20 & .806 & & & & & .68 & \\
\hline Madde 18 & .778 & & & & & .62 & \\
\hline Madde 15 & .777 & & & & & .61 & \\
\hline Madde 19 & .765 & & & & & .61 & \\
\hline Madde 16 & .764 & & & & & .59 & \\
\hline Madde 17 & .743 & & & & & .58 & \\
\hline Madde 1 & & .859 & & & & .75 & \\
\hline Madde 4 & & .855 & & & & .74 & \\
\hline Madde 7 & & .854 & & & & .76 & \\
\hline Madde 3 & & .846 & & & & .73 & \\
\hline Madde 6 & & .845 & & & & .76 & \\
\hline Madde 2 & & .836 & & & & .72 & \\
\hline Madde 5 & & .835 & & & & .73 & \\
\hline Madde 25 & & & .846 & & & .72 & \\
\hline Madde 23 & & & .813 & & & .66 & \\
\hline Madde 24 & & & 699 & & & .53 & \\
\hline Madde 26 & & & .655 & & & .47 & \\
\hline Madde 22 & & & .650 & & & .44 & \\
\hline Madde 8 & & & & .883 & & .78 & \\
\hline Madde 9 & & & & .865 & & .75 & \\
\hline Madde 11 & & & & .681 & & .49 & \\
\hline Madde 13 & & & & .620 & & .46 & \\
\hline
\end{tabular}

Tablo 4'te, ölçekte bulunan maddelerin aldığı faktör yüklerinin .620 ile .859 değerleri arasında olduğu görülmektedir. Costello ve Osborne (2005) faktör yükü .50 üzerinde olan maddelerin güçlü yük değerine sahip olduğunu ifade etmektedir. Ortak faktör varyanslarına ilişkin değerler incelendiğinde tüm maddelerin ortak varyansa yeterli düzeyde katkı sağladığı görülmektedir. Açımlayıcı faktör analizi sonucunda elde edilen dört faktör, maddelerin içerikleri göz önünde tutularak adlandırılmıştır. Belirlenen boyutlar ve bu boyutlarda yer alan maddeler Tablo 5 'te verilmiştir. 
Tablo 5. AFA Sonucunda Elde Edilen Boyutlar ve Bu Boyutlar Altında Toplanan Maddeler

\begin{tabular}{lcc}
\hline Boyutlar & Madde Sayısı & Maddeler \\
\hline İşbirlikçi Ortam & 6 & $15,16,17,18,19,20$ \\
Okul Müdürü Desteği & 7 & $1,2,3,4,5,6,7$ \\
Okul İmkânları & 5 & $22,23,24,25,26$ \\
Mesleki İlgi & 4 & $8,9,11,13$ \\
\hline
\end{tabular}

Tablo 5 incelendiğinde "İşbirlikçi Ortam” boyutunda altı madde $(15,16,17,18,19,20)$; “Okul Müdürü Desteği” boyutunda yedi madde (1,2,3,4,5,6,7); “Okul İmkânları” boyutunda beş madde $(22,23,24,25,26)$ ve "Mesleki İlgi" boyutunda dört madde $(8,9,11,13)$ yer aldı̆̆ görülmektedir.

\section{Birinci Düzey Doğrulayıcı Faktör Analizi}

AFA ile belirlenen 22 madde ve dört faktörden oluşan yapının doğrulanması ve model veri uyumunun test edilmesi amacıyla, 310 öğretmenin oluşturduğu ikinci çalışma grubundan elde edilen verilerle birinci düzey DFA gerçekleştirilmiştir. Analiz sonucunda öncelikle, değişkenlere ilişkin $\mathrm{t}$ değerleri incelenmiştir. T değerlerinin 1.96'yı geçmesi durumunda 05 düzeyinde, 2.56'yı geçmesi durumunda ise .01 düzeyinde anlamlı olduğu ve anlamlılık göstermeyen maddelerin ölçekten çıkarılması gerektiği ifade edilmektedir (Çokluk, Şekercioğlu ve Büyüköztürk, 2010). Mevcut dört boyutlu model için t değerleri 9.34 ile 18.86 arasında bulunmuştur. Bu bulguya göre her bir maddenin $\mathrm{t}$ değerinin .01 düzeyinde anlamlı olduğu ve modelden madde çıkarılmasına gerek olmadığı belirlenmiştir. Daha sonra OÖİÖ’ye ilişkin uyum iyiliği değerleri hesaplanmıştır. Yapılan işlem sonucunda elde edilen uyum iyiliği değerleri Tablo 6'da sunulmuştur.

Tablo 6. OÖİÖ’nün Birinci Düzey DFA Sonucunda Hesaplanan İyiliği Değerleri

\begin{tabular}{cccccccccc}
\hline$\chi^{2}$ & $\mathrm{sd}$ & $\chi 2 / \mathrm{sd}$ & RMSEA & RMR & GFI & AGFI & CFI & NFI & TLI \\
\hline 434.24 & 203 & 2.14 & .06 & .05 & .89 & .86 & .95 & .91 & .94 \\
\hline
\end{tabular}

Tablo 6 incelendiğinde, Ki-kare değerinin $\chi 2=434$, serbestlik derecesinin ise sd=203 şeklinde hesaplandığı görülmektedir. Değerler oranlandığında $\chi 2 / \mathrm{sd}=2.14$ değeri elde edilmiştir. Bu değerin 3'ün altında olması mükemmel uyumun, 5'in altında olması ise orta düzeyde uyumun göstergesi olarak değerlendirilmektedir (Jöreskog ve Sörbom, 1993). Bu bulguya göre, mevcut model için hesaplanan $\chi 2 / s d$ değeri iyi uyum göstermektedir. DFA'da sık kullanılan bir uyum indeksi olan RMSEA değerinin .05'ten küçük olması iyi uyumun, .08'den küçük olması ise kabul edilebilir uyumun göstergesidir (Browne ve Cudeck, 1993; 
Kline, 1994). Mevcut model için .06 olarak hesaplanan RMSEA değeri yeterli uyuma işaret etmektedir. DFA sonucunda $\mathrm{RMR}=.05$ olarak hesaplanmıştır. RMR değerinin .05 'ten az olması iyi uyumu, .10'dan az olması ise kabul edilebilir uyumu göstermektedir (Hu ve Bentler, 1995). Mevcut model için hesaplanan RMR değerinin iyi uyumun bir göstergesi olduğu belirlenmiştir. OÖİÖ'ne ilişkin diğer uyum indeksi değerleri CFI=.95, NFI=.91, TLI=.94, GFI=.89 ve AGFI=.86 olarak bulunmuştur. CFI, NFI, TLI, GFI, AGFI değerleri için .90 üstü değerler kabul edilebilir uyumu, .95 üstü değerler ise mükemmel uyumu göstermektedir (Çokluk, Şekercioğlu ve Büyüköztürk, 2010; Schumacker ve Lomax, 2004; Sümer, 2000). Ancak örneklem büyüklüğünden etkilenmelerinden dolayı GFI ve AGFI değerlerinin modele ilişkin uyumun değerlendirilmesinde .85 ve üzerinde aldığ değerlerin de kabul edilebilir olduğu belirtilmektedir (Anderson ve Gerbing, 1984; Bryant, Yarnold ve Grimm, 1996; Schermelleh-Engel ve Moosbrugger, 2003). Alanyazındaki bu bilgilere göre mevcut model için hesaplanan CFI uyum iyiliği değerinin iyi bir uyuma; NFI, TLI, GFI ve AGFI değerlerinin ise kabul edilebilir bir uyuma işaret ettiği olduğu ifade edilebilir. DFA sonucunda ortaya çıkan dört faktörlü modelin faktör yükleri ve yol diyagramı Şekil 2'de verilmektedir.

Şekil 2'de standardize edilmiş değerler incelendiğinde faktörler arası ilişki değerlerinin .42 ile .75 arasında değiştiği görülmektedir. Maddelere ilişkin faktör yükleri ise işbirlikçi ortam boyutu için .72 ile .86; okul müdürü desteği boyutu için .80 ile .88; okul imkânları boyutu için .61 ile .73 ve mesleki ilgi boyutu için .73 ile .85 arasında değişmektedir. Tüm maddelerin faktör yüklerinin . 50'nin üzerinde olması ölçekteki her bir maddenin ait olduğu faktörü iyi derecede temsil ettiğini göstermektedir (Fornell ve Larcker, 1981). 


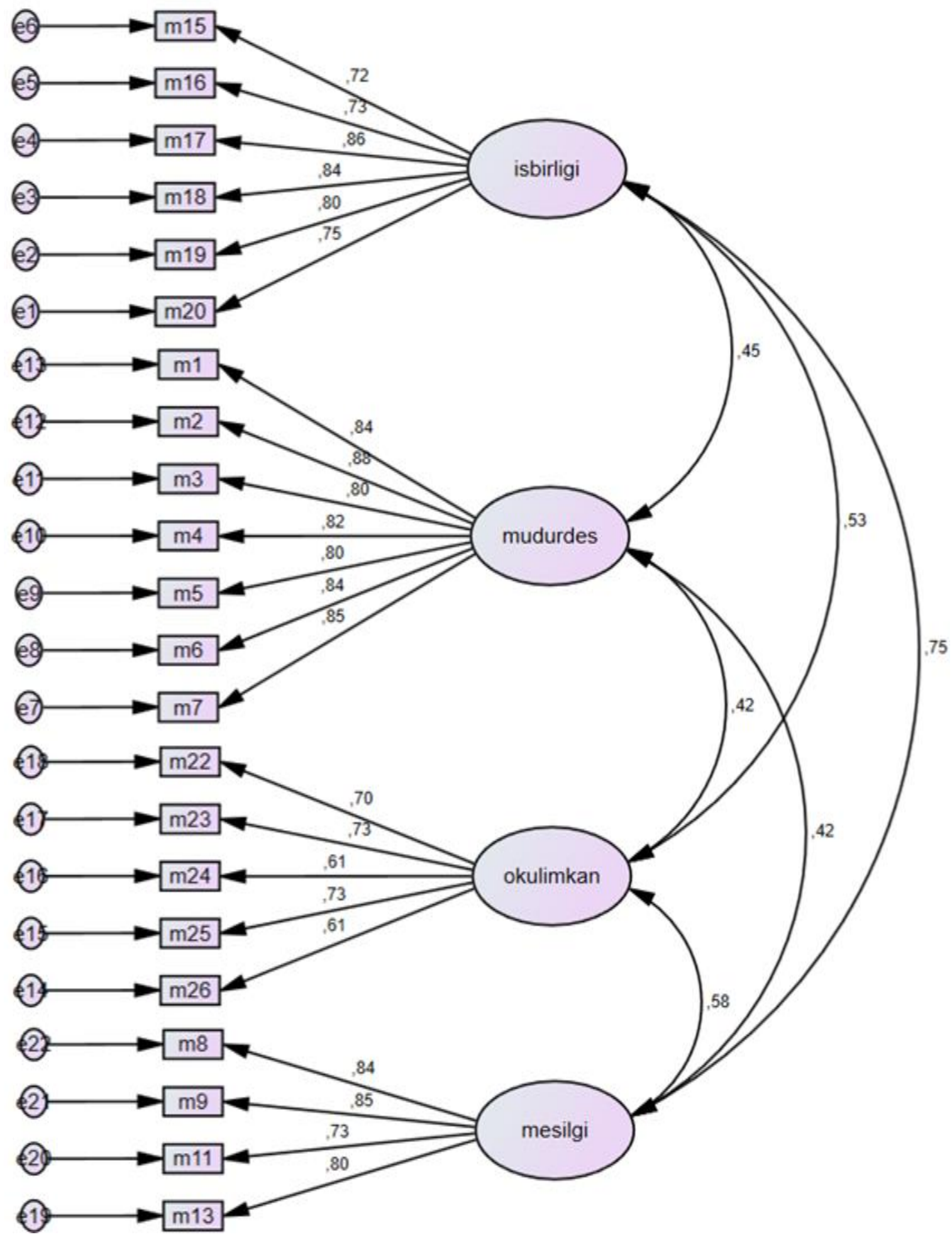

Şekil 2. OÖIÖ’nün Birinci Düzey DFA sonuçları

\section{İkinci düzey doğrulayıcı faktör analizi}

Çok faktörlü ölçeklerin ikinci düzey çok faktörlü modellerinin de sınanması gerektiği ifade edilmektedir (Meydan ve Şeşen, 2011). Bu bağlamda, birinci düzey DFA ile elde edilen “İşbirlikçi Ortam”, Okul Müdürü Desteği”, “Okul İmkânları” ve "Mesleki İlgi” boyutlarının 
birlikte daha kapsayıcı bir üst kavram olan "Öğrenme İklimi” faktörü altında birleşip birleşmediğini belirlemek için ikinci düzey DFA gerçekleştirilmiştir. Birinci düzey DFA ile test edilen 4 gizil ve 22 gösterge değişkenli modele, ikinci düzey öğrenme iklimi gizil değişkeni eklenerek ikinci düzey çok faktörlü modelin sınanması sonucunda elde edilen uyum iyiliği değerleri Tablo 7'de verilmiştir.

Tablo 7. OÖIÖ’nün İkinci Düzey DFA Sonucunda Hesaplanan Iyiliği Değerleri

\begin{tabular}{cccccccccc}
\hline$\chi^{2}$ & $\mathrm{sd}$ & $\chi 2 / \mathrm{sd}$ & RMSEA & RMR & GFI & AGFI & CFI & NFI & TLI \\
\hline 439.26 & 205 & 2.14 & .06 & .05 & .88 & .86 & .95 & .91 & .94 \\
\hline
\end{tabular}

Tablo 7 incelendiğinde, ikinci düzey DFA sonucunda uyum indekslerinin $\chi 2=439.26$ $(\mathrm{sd}=205, \mathrm{p}<.001),(\chi 2 / \mathrm{sd})=2.14, \mathrm{RMSEA}=.06, \mathrm{RMR}=.05, \mathrm{GFI}=.88, \mathrm{AGFI}=.86, \mathrm{CFI}$ $=.95, \mathrm{NFI}=.91, \mathrm{TLI}=.94$ olarak bulunduğu görülmektedir. Elde edilen bu değerler dört faktörlü modelin iyi ve kabul edilebilir düzeyde uyum gösterdiğini ortaya koymaktadır (Anderson ve Gerbing, 1984; Jöroskog ve Sörbom, 1993; Kline, 1994; Schumacker ve Lomax, 2004). İkinci düzey DFA faktör-ölçek ilişkisini gösteren yol diyagramı Şekil 3'de verilmiştir.

Şekil 3 incelendiğinde, ikinci düzey DFA sonucu elde edilen standardize edilmiş yol katsayılarının .52 ile .87 arasında olduğu görülmektedir. Okullarda Öğrenme İklimi’ni en iyi açıklayan alt faktörler sırasıyla mesleki ilgi (.87), işbirlikçi ortam (.85), okul imkânları (.66) ve okul müdürü desteğidir (.52). Ayrıca ikinci düzey DFA sonuçlarına göre faktörlere ilişkin $\mathrm{t}$ değerleri işbirlikçi ortam boyutu için 9.52, okul müdürü desteği boyutu için 7.62, okul imkânları boyutu için 7.41 ve mesleki ilgi boyutu için 9.53 olarak, $\mathrm{p}<.01$ düzeyinde anlamlı bulunmuştur. T değerlerinin anlamlı olması modelin kabul edilebilirliğinin bir göstergesidir (Schumacker ve Lomax, 2004). Tüm bu bulgulardan hareketle 22 madde ve dört boyuttan oluşan OÖIÖ’nün yeterli uyum iyiliğine sahip ve geçerli olduğu ileri sürülebilir. 


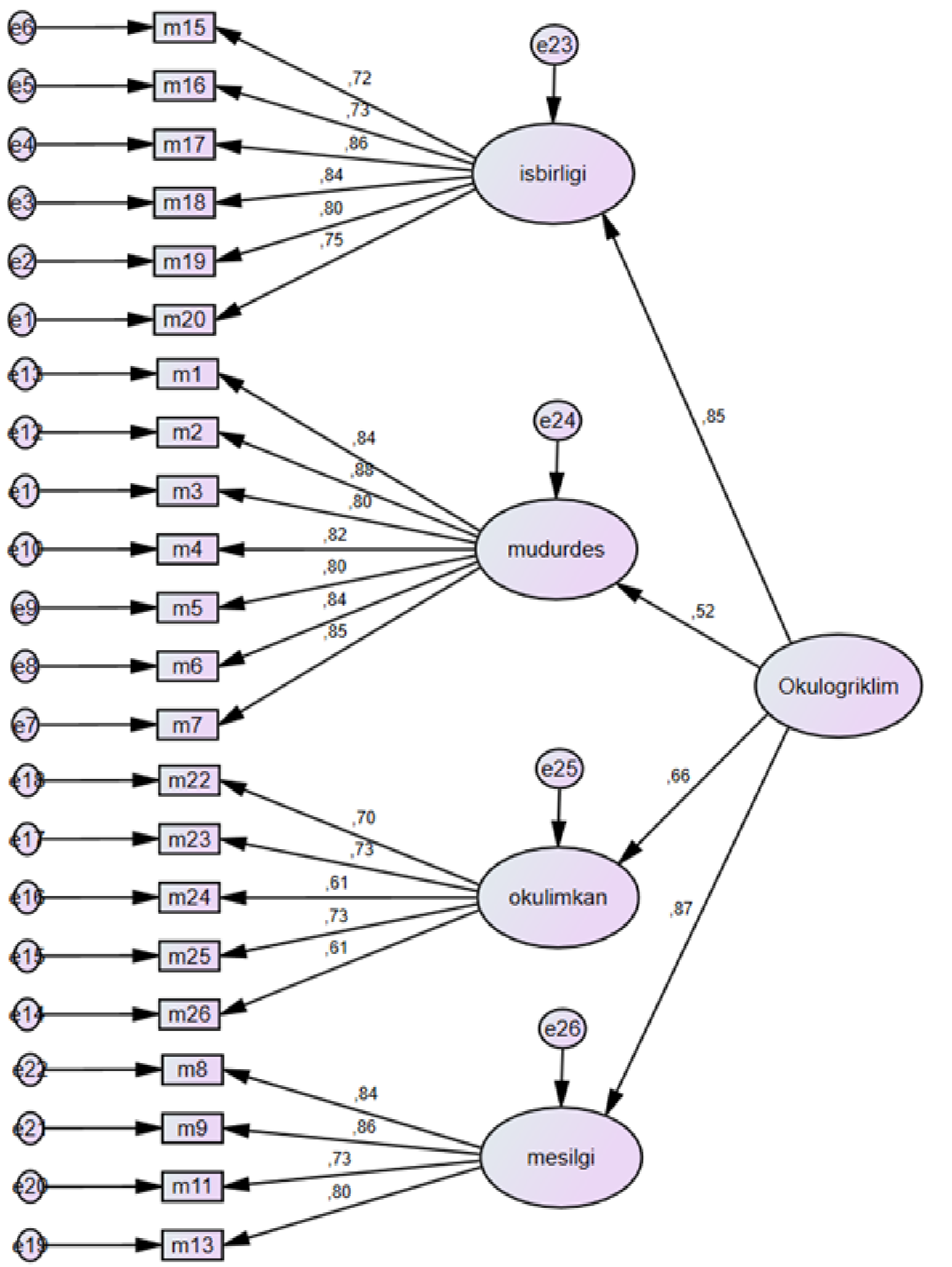

Şekil 3. OÖIÖ’nün İkinci Düzey DFA sonuçları 


\section{Güvenirlik Çalışmalarına İlişkin Bulgular}

Likert tipi ölçeklerde iç tutarlığın sınanması gerekmektedir. Bunun için en uygun yol Cronbach Alfa güvenirlik katsayılarının hesaplanmasıdır (Tezbaşaran, 2008). Bu doğrultuda, OÖİÖ’nün tümünün ve alt boyutlarının güvenirliğini belirlemek amacıyla Cronbach Alfa değerleri hesaplanmıştır. Ölçeğin tümü ve alt boyutları için hesaplanan Cronbach alfa iç tutarlılık katsayıları Tablo 8'de verilmiştir.

Tablo 8. OÖIÖ’nün ve Alt Boyutlarının İç Tutarlılık Katsayıları

Boyutlar Madde sayısı Cronbach Alfa değeri

\begin{tabular}{lcc}
\hline İşbirlikçi Ortam & 6 & .91 \\
Okul Müdürü Desteği & 7 & .94 \\
Okul İmkânları & 5 & .80 \\
Mesleki İlgi & 4 & .86 \\
Ölçeğin Tümü & 22 & .93 \\
\hline
\end{tabular}

Tablo 8 incelendiğinde OÖİÖ’nün Cronbach alfa değerleri işbirlikçi ortam boyutunda $\alpha=.91$, okul müdürü desteği boyutunda $\alpha=.94$, okul imkânları boyutunda $\alpha=.80$ ve mesleki ilgi boyutunda $\alpha=.86$ olarak hesaplandığı görülmektedir. Ölçeğin tümü için Cronbach alfa iç tutarlılık katsayısı .93 olarak hesaplanmıştır. Cronbach Alfa katsayısının .70'den yüksek olmasının ölçme aracının güvenirliği açısından yeterli olduğu öne sürülmektedir (Fraenkel ve Wallen, 2006; Nunnally, 1978; Şencan, 2005). Bu nedenle, OÖİÖ’nün güvenilir bir ölçme aracı olduğu ifade edilebilir. Ölçeğin iç tutarlılığını belirlemek amacıyla faktörlerin birbirleriyle ve ölçeğin tümüyle olan korelasyonları hesaplanmıştır. Korelasyon analizine ilişkin sonuçlar Tablo 9'da verilmektedir.

Tablo 9. Boyutların Birbiriyle ve Ölçek Toplam Puanıyla İlişkilerine Yönelik Pearson Momentler Çarpım Korelasyon Katsayıları

\begin{tabular}{lccccc}
\hline \multicolumn{1}{c}{ Boyutlar } & 1 & 2 & 3 & 4 & 5 \\
\hline 1-İsbirlikçi Ortam & 1 & & & \\
2-Okul Müdürü &, $427^{* *}$ & 1 & & \\
Desteği & & & & \\
3-Okul İmkânları &, $506^{* *}$ &, $448^{* *}$ & 1 & 1 \\
4-Mesleki İlgi &, $651^{* *}$ &, $314^{* *}$ &, $415^{* *}$ &, $691^{* *}$ & 1 \\
5-ÖlçekToplam Puanı &, $806^{* *}$ &, $809^{* *}$ &, $741^{* *}$ & & \\
\hline
\end{tabular}

$* * \mathrm{p}<0.01$ 
Tablo 9' da, ölçeğin tüm alt boyutlarının birbiriyle ve ölçeğin tümüyle arasındaki ilişkilerin $\mathrm{p}<0.01$ düzeyinde anlamlı olduğu görülmektedir. Boyutlar arasındaki korelasyon değerleri .31 ile .65 arasında değişmektedir. Faktörler arası korelasyon düzeyinin çok yüksek ya da düşük olması istenen bir durum değildir (Çokluk, Şekercioğlu ve Büyüköztürk, 2010). Faktörler arasındaki ilişkinin .80'den küçük olması ölçeğin ayırt edici geçerliğinin sağlandığını göstermektedir (Brown, 2006). Mevcut bulgulara göre ölçeğin alt boyutlarının birbirleri arasında pozitif yönde orta düzeyde ilişkili göstermesi ölçekteki her bir alt boyutun ayrı özelliği ölçtüğü şeklinde yorumlanabilir. Ayrıca ölçeği oluşturan alt boyutlar ile ölçeğin tümü arasında yüksek düzeyde anlamlı ilişkiler olduğu saptanmıştır. Bu bulgunun ölçeğin kendi içinde tutarlılığının ve güvenirliğinin bir başka göstergesi olduğu ifade edilebilir.

\section{Tartışma ve Sonuç}

$\mathrm{Bu}$ araştırmada, öğretmenlerin öğrenme iklimine yönelik algılarını ortaya koyan geçerli ve güvenilir bir ölçme aracının geliştirilmesi amaçlanmıştır. Bu doğrultuda, öncelikle öğrenme iklimine ilişkin alanyazın detaylı bir biçimde taranmış ve daha önceden konuya ilişkin geliştirilen ölçme araçları incelenmiştir (Bartram vd., 1993; Hoyle 1972; Nikolova vd., 2014; Opfer, Pedder ve Lavicza 2011). Alanyazındaki bilgilere dayalı olarak ölçeğin dört boyuttan oluşabileceği öngörülmüştür. Ölçeğin geçerlik çalışmaları için madde analizi, açımlayıcı faktör analizi, birinci ve ikinci düzey doğrulayıcı faktör analizleri yapılmış, güvenirlik çalışmasında ise Cronbach alfa değerleri kullanılmıştır. 279 öğretmenden oluşan birinci çalışma grubundan elde edilen verilerle AFA, 310 öğretmenden oluşan ikinci çalışma grubundan elde edilen verilerle birinci düzey ve ikinci düzey DFA yapılmıştır. Yapılan analizler sonucunda öngörüldüğü gibi dört faktörden oluşan 22 maddelik bir ölçek elde edilmiştir. Elde edilen boyutlar işbirlikçi ortam, okul müdürü desteği, okul imkânları ve mesleki ilgi olarak isimlendirilmiştir. AFA sonucu elde edilen dört faktörlü modelin verilerle uyumunu ve doğrulanıp doğrulanmadığını belirlemek amacıyla yapılan birinci ve ikinci düzey DFA, elde edilen dört faktörlü modelin kabul edilebilir seviyede yapı geçerliğine sahip olduğu ve ölçeğin dört faktörlü yapısının doğrulandığını göstermiştir (Jöroskog ve Sörbom, 1993; Hu ve Bentler, 1995; Schumacker ve Lomax, 2004).

OÖIÖ’nün tümünün ve alt boyutlarının güvenirliğini belirlemek amacıyla Cronbach alfa değerleri incelenmiştir. Ölçeğin tümü için Cronbach Alfa iç tutarlılık katsayısı 93 olarak hesaplanmıştır. Ölçeğin alt boyutları için işbirlikçi ortam boyutunda $\alpha=.91$, okul müdürü desteği boyutunda $\alpha=.94$, okul imkânları boyutunda $\alpha=.80$ ve mesleki ilgi 
boyutunda $\alpha=.86$ olarak bulunmuştur. Bu bulgular, OÖİÖ'nün güvenilir bir ölçme arac1 olduğunu ortaya koymuştur (Fraenkel ve Wallen, 2006). Son olarak boyutlar arasındaki korelasyon değerleri hesaplanarak katsayıların .31 ile .65 arasında değiştiği görülmüştür. Faktörler arasındaki ilişkinin .80 'den küçük olması ölçeğin ayırt edici geçerliğinin sağlandığını göstermektedir (Brown, 2006).

Yapılan analizler sonucunda mevcut çalışma kapsamında geliştirilen OÖİÖ’nün okullarda öğrenme iklimine yönelik öğretmen algılarının belirlenmesinde kullanılabilecek geçerli ve güvenilir bir ölçme aracı olduğu söylenebilir. 22 madde ve dört boyuttan oluşan ölçek beşli Likert ( 1 =hiçbir zaman, 2=nadiren, 3=bazen, 4=sıklıkla, 5=her zaman) tipindedir. Ölçekten elde edilebilen en düşük puan 22, en yüksek puan ise 110 'dur ve ölçekte ters puanlanan madde yer almamaktadır. Ölçekten alınan puanların artması, öğretmenlerin görev yaptıkları okullarda var olan öğrenme iklimine ilişkin alg1 düzeylerinin de arttığı anlamına gelmektedir. Ölçeğin, öğretmen öğrenmesine yönelik okul özelliklerinin belirlenmesine yönelik araştırmalara katkı sağlayacağı düşünülmektedir. Ölçeğin farklı örneklemler üzerinden uygulanması durumunda geçerlik ve güvenirlik analizlerinin yinelenmesi alanyazına katkı sağlayabilir. Ayrıca gelecek çalışmalarda ölçeğin özel okul öğretmenleri üzerinde geçerlik ve güvenirlik çalışmalarının yinelenmesi önerilebilir.

\section{Sinırlılıklar}

$\mathrm{Bu}$ araştırmanın bazı sınırlılıkları bulunmaktadır. İlk olarak, ölçme aracının geçerliği açımlayıcı ve doğrulayıcı faktör analizleri ile yapılmış olup, ölçüt bağıntılı bir geçerlik sınaması gerçekleştirilmemiştir. Bu sınırlılık, izleyen çalışmalarda giderilebilir. İkinci olarak, araştırmanın verileri kamu okullarında görevli öğretmenler üzerinde yürütülmüştür. Kamu okulları ile özel okulların öğretmenler için sağladıkları öğrenme olanaklarının farklılığ̣ dikkate alındığında, özel okul öğretmenlerinin öğrenme iklimine ilişkin özelliklerinin bu araştırma grubunda temsil edilmemesi bir sınırlılık olabilir. Bu noktada gelecek çalışmalarda özel okul öğretmenleri üzerinde geçerlik ve güvenirlik çalışmalarının yinelenmesi uygun olabilir.

Etik Kurul İzin Bilgisi: Bu araştırma Hacettepe Üniversitesi Senatosu Etik Komisyonunun 09.06.2020 tarihli toplantısı 35853172-600 sayılı kararı ile alınan izinle yürütülmüştür.

Yazar Çıkar Çatışması Bilgisi: Yazar çıkar çatışması bulunmamaktadır. 
Yazar Katkısı: Birinci yazar Gökhan SAVAŞ; kaynak taramasının yapılması, verilerin toplanması, verilerin analizi ve makale yazımına katkıda bulunmuştur. İkinci yazar Doç. Dr. Nihan DEMIRKASIMOĞLU; çalışma için fikir oluşturulması, çalışma yönteminin belirlenmesi, makale yazımı ve makalenin gönderim öncesi değerlendirilmesine katkıda bulunmuştur.

\section{Kaynakça}

Aldridge, J. M., Laugksch, R. C., \& Fraser, B. J. (2006). School-level environment and outcomes-based education in South Africa. Learning Environments Research, 9(2), 123-147.

Anderson, J.C., \& Gerbing D.W. (1984). The effect of sampling error on convergence, improper solutions, and goodness-of- fit indices for maximum likelihood confirmatory factor analysis. Psychometrika, 49, 155-173.

Atwal, K. (2013). Theories of workplace learning in relation to teacher professional learning in UK primary schools. Research in Teacher Education, 3(2), 22-27.

Bama, M. C. (1999). The relationship between students' perceptions of the school learning climate of a community of caring high school and selected characteristics of students and teachers. (Unpublished doctoral dissertation), Morgan State University, Maryland.

Bandura, A. (1991). Social cognitive theory. Organizational Behavior and Human Decision Processes, 50 (2), 248-287.

Bartram D., Foster J., Lindley PA., Brown AJ., \& Nixon S. (1993). Learning climate questionnaire (LCQ): Background and technical information. Oxford: Employment Service and Newland Park Associates Limited.

Bates, R., \& Khasawneh, S. (2005). Organizational learning culture, learning transfer climate and perceived innovation in Jordanian organizations. International Journal of Training and Development, 9(2), 96-109. Doi. 10.1111/j.1468-2419.2005.00224.

Bora, N. (2010). Uluslararası bakalorya diploma programının (IB) öğretmen ve ögrencilerin öğrenme iklimi ile ilgili algıları üzerindeki etkisi. Yayımlanmamış yüksek lisans tezi, Maltepe Üniversitesi, İstanbul. 
172

G.Savaş ve N.Demirkasımoğlu/ Pamukkale Üniversitesi Eğitim Fakültesi Dergisi, 52, 147-178, 2021

Bowen, D. D., \& Kilmann, R. H. (1975). Developing a comparative measure of the learning climate in professional schools, Journal of Applied Psychology, 60, 71-79.

Bozdoğan, K. (2010) İlköğretim okulu müdürlerinin liderlik davranışlart ile okulun öğrenme ikliminin karşılaştırılması, Yayımlanmamış yüksek lisans tezi, Niğde Üniversitesi, Niğde.

Bozdoğan, K. ve Sağnak, M. (2011). İlköğretim okulu müdürlerinin liderlik davranışları ile öğrenme iklimi arasındaki ilişki. Abant İzzet Baysal Üniversitesi Eğitim Fakültesi Dergisi, 11(1), 137-145.

Büyüköztürk, Ş. (2012). Sosyal bilimler için veri analizi el kitabı. Ankara: Pegem Akademi.

Büyüköztürk, Ş., Çakmak E., Akgün Ö., Karadeniz Ş. ve Demirel F. (2016). Bilimsel araştırma yöntemleri. Ankara: Pegem.

Bryant, F. B., Yarnold, P. R., \& Grimm, L. G. (1996). Toward a measurement model of the affect intensity measure: A three-factor structure. Journal of Research in Personality, 30(2), 223-247. Doi. 10.1006/jrpe.1996.0015.

Brown, T. A. (2006). Confirmatory factor analysis for applied research. New York, NY: Guilford Press.

Browne, M. W., \& Cudeck, R. (1993). Alternative ways of assessing model fit. In: K. A. Bollen\& J. S. Long (Eds.), Testing structural equation models (pp. 136-162). Beverly Hills, CA: Sage.

Cattell, R. B. (1978). The scientific use of factor analysis in behavioral and life sciences. New York: Plenum.

Cherkowski, S. (2016). Exploring the role of the school principal in cultivating a professional learning climate. Journal of School Leadership, 26(3), 523-543. Doi. $10.1177 / 105268461602600306$

Comrey, A., \& Lee, H. (1992). Interpretation and application of factor analytic results. In A. Comrey, \& H. Lee (Eds.), A first course in factor analysis. USA: Psychology Press, New York.

Cortini, M. (2016). Workplace identity as a mediator in the relationship between learning climate andjob satisfaction during apprenticeship: suggestions for HR practitioners, Journal of Workplace Learning, 28(2), 54-65. Doi. 10.1108/JWL-12-2015-0093. 
Costello, A., \& Osborne, J. (2005). Best practices in exploratory factor analysis: Four recommendations for getting the most from your analysis. Practical Assessment, Research And Evaluation, 10 (7), 1-9.

Çamur, A. (2006). Liselerde öğrenme iklimine ilişkin yönetici, öğretmen, veli ve ögrenci görüşleri, Yayımlanmamış yüksek lisans tezi, Ege Üniversitesi, İzmir.

Çokluk, Ö., Şekercioğlu, G. ve Büyüköztürk, Ş. (2010). Sosyal bilimler için çok değişkenli istatistik: SPSS ve LISREL uygulamaları. Ankara: Pegem.

Damico, S. B., \& Roth, J. (1993). General Track Students' Perceptions of School Policies and Practices. Journal of Research and Development in Education, 27(1), 1-8.

Deal, T. E., \& Peterson, K. D. (1999). Shaping school culture: The heart of leadership. San Francisco, CA: Jossey-Bass.

Denison, D. R. (1996). What is the difference between organizational culture and organizational climate? A native's point of view on a decade of paradigm wars. Academy of Management Review, 21(3), 619-654.

DeVellis, R. F. (2003). Scale development: Theory and applications. Newbury Park: Sage Publications.

Eldor, L., \& Harpaz, I. (2016). A process model of employee engagement: The learning climate and its relationship with extra-role performance behaviors. Journal of Organizational Behavior, 37(2), 213-235. Doi.10.1002/job.2037.

Ellis, R. J. (1988). Self-monitoring and leadership emergence in groups. Personality and Social Psychology Bulletin, 14(4), 681-693. Doi. 10.1177/0146167288144004.

Field, A. (2013). Discovering statistics using IBM SPSS statistics (4th ed.). London: Sage.

Fornell, C., \& Larcker, D. F. (1981). Evaluating structural equation models with unobservable variables and measurement error. Journal of Marketing Research, $18(1), 39-50$.

Fraenkel, J.R., \& Wallen, N.E. (2006). How to design and evaluate research in education. New York: Mc Graw-Hill.

Gerold, R. A., \& Barnes, D. R. (1986). Elementary School Level Students' Perceptions of Their School World. (ERIC Document Reproduction Dervice No: ED269154) 
Hallinger, P., Bickman, L., \& Davis, K. (1996). School context, principal leadership, and student reading achievement. The Elementary School Journal, 96(5), 527-549.

Hetland, H., Skogstad, A., Hetland, J., \& Mikkelsen, A. (2011). Leadership and learning climate in a work setting. European Psychologist, 16, 163-173. Doi:10.1027/10169040/a000037.

Hinkin, T. R. (1995). A review of scale development practices in the study of organizations. Journal of Management, 21(5), 967-988.

Hodkinson, H., \& Hodkinson, P. (2005). Improving schoolteachers' workplace learning. Research papers in education,20(2), 109-131. Doi: $10.1080 / 02671520500077921$

Hollingsworth, H. (1999). Teacher professional growth: A study of primary teachers involved in mathematics professional development, Unpublished doctoral thesis, Deakin University, Burwood, Australia.

Honey, P., \& Mumford, A. (1996). How to manage your learning environment. Peter Honey, Maidenhead

Hoyle, J. R. (1972). Learning environments: Space and perceptions. College Station: Texas A\&M University. (ERIC Document Reproduction Service No: ED117815)

Hu, L.T., \& Bentler, P. M. (1995). Evaluating model fit. In R. H. Hoyle (Eds.), Structural equation modeling: Concepts, issues and applications, (pp.76-99). Thousand Oaks, CA: Sage

Johnson, D.W., \& Johnson, R.T. (1999). Learning together and alone: Cooperative, competitive, and individualistic learning (5th ed.). New York: Allyn \& Bacon.

Jöreskog, K. G., \& Sörbom, D. (1993). LISREL 8: Structural equation modeling with the simplis command language. Lincolnwood: Scientific Software International, Inc.

Kanadlı, S., ve Bağçeci, B. (2016). Öğretmenlerin kişiler arası motivasyon stilleri: Öğrenme İklimi Ölçeği’nin Türkçe versiyonu. Anadolu Üniversitesi Sosyal Bilimler Dergisi, $16(1), 1-12$.

Kaplan, L. S., \& Geoffroy, K. E. (1990). Enhancing the school climate: New opportunities for the counselor. The School Counselor, 38(1), 7-12. 
Karasar, N. (1999). Bilimsel araştırma yöntemi - kavramlar, ilkeler, teknikler. Ankara: Nobel.

Kline, P. (1994). An easy guide to factor analysis. London: Routledge.

Koops B. J., \& Winsor, K. (2006). Creating a Professional Learning Culture, The Journal of Education, 186 (3), 61-70.

Lezotte, L. W., Hathaway, D. V., Miller, S. K., Passalacqua, J., \& Brookover, W. B. (1980). School learning climate and student achievement. Tallahassee: Florida State University Foundation.

Liu, Y., Ding, C., Berkowitz, M. W., \& Bier, M. C. (2014). A psychometric evaluation of a revised school climate teacher survey. Canadian Journal of School Psychology, 29(1), 54-67. Doi. 10.1177/0829573514521777.

Liu, S., Hallinger, P., \& Feng, D. (2016). Supporting the professional learning of teachers in China: Does principal leadership make a difference?, Teaching and Teacher Education, 59 (2016), 79-91. Doi. https://doi.org/10.1016/j.tate.2016.05.023.

Lowe, J. (1990) The interface between educational facilities and learning climate in three elementary schools, Unpublished doctoral dissertation, Texas A\&M University, College Station, TX, USA.

Marsick, V. J., \& Watkins, K. E. (2003). Demonstrating the value of an organization's learning culture: the dimensions of the learning organization questionnaire. Advances in Developing Human Resources, 5(2), 132-151. Doi: $10.1177 / 1523422303005002002$.

Masitsa, M.G. (2005). The principal's role in restoring a learning culture in township secondary schools, Africa Education Review, 2(2), 205-220, Doi: $10.1080 / 18146620508566301$.

Meydan, C. H. ve Şeşen, H. (2011). Yapısal eşitlik modellemesi Amos uygulamaları. Ankara: Detay.

Mikkelsen, A., \& Grønhaug, K. (1999). Measuring organizational learning climate: A crossnational replication and instrument validation study among public sector employees. Review of public personnel administration, 19(4), 31-44. Doi. 10.1177/0734371X9901900404 
Moreland, J. Y. (1984). A study of the relationships among student achievement, school learning climate, and personality types of elementary school principals, Unpublished doctoral dissertation, Georgia State University, Georgia.

Nikolova, I., Van Ruysseveldt, J., De Witte, H., \& Van Dam, K. (2014). Learning climate scale: Construction, reliability and initial validity evidence. Journal of Vocational Behavior, 85(3), 258-265. Doi. 10.1016/j.jvb.2014.07.007.

Nunnally, J. C. (1978). Psychometric theory (2nd ed.). New York: McGraw-Hill.

O'Donnell, R. J., \& White, G. P. (2005). Within the accountability era: Principals' instructional leadership behaviors and student achievement. NASSP bulletin, 89(645), 56-71.

Opfer, V. D., Pedder, D. J., \& Lavicza, Z. (2011). The influence of school orientation to learning on teachers' professional learning change. School Effectiveness and School Improvement, 22(2), 193-214. Doi.10.1080/09243453.2011.572078.

Oluremi, O. (2008), Principals' leadership behavior and school learning culture in Ekiti state secondary schools, The Journal of International Social Research, 1(3), 301-311.

Öğdem, Z. (2015). Mesleki öğrenme topluluğu olarak ilköğretim okullarında takım liderliği ve örgüt iklimi, Yayımlanmamış doktora tezi, Gazi Üniversitesi, Ankara.

Pan, Y. H. (2014). Relationships among teachers' self-efficacy and students' motivation, atmosphere, and satisfaction in physical education. Journal of Teaching in Physical Education, 33(1), 68-92. Doi. 10.1123/jtpe.2013-0069.

Perry, N. E., \& Rahim, A. (2011). Studying self-regulated learning in classrooms. In B. J. Zimmerman \& D. H. Schunk (Eds.), Handbook of self-regulation of learning and performance (pp. 122-136). New York, NY: Taylor \& Francis.

Prieto, I.M., \& Revilla, E. (2006). Formal and informal facilitators of learning capability: the moderating effect of learning climate. IE Working Paper.

Resendiz, B. (1994). Comparison of school learning in selected chapter I and non-chapter I schools in the northside independent school district, Unpublished doctoral dissertation, Texas A \& M University, Texas.

Rousseau, D. M. (1988). The construction of climate in organizational research. International Review of Industrial and Organizational Psychology, 10, 139-146. 
Schein, E. H. (1990). Organizational culture. American Psychologist, 45, 109-119.

Schermelleh-Engel, K., Moosbrugger, H. \& Müller, H. (2003). Evaluating the fit of structural equation models: Test of significance and descriptive goodness-of-fit measures. Methods of Psychological Research-Online, 8(2), 23-74.

Schunk, D. H., \& Pajares, F. (2009). Self-efficacy theory. In K. R. Wentzel, \& A. Wigfield (Eds.), Handbook of motivation at school (pp. 49-68). Routledge.

Shoshani, A. \& Eldor, L. (2016). The informal learning of teachers: Learning climate, job satisfaction and teachers' and students' motivation and well-being. International Journal of Educational Research, 79, 52-63. Doi. 10.1016/j.ijer.2016.06.007

Schumacker, R. E., \& Lomax, R. G. (2004) A beginner's guide to structural equation modeling. New Jersey. Lawrence Erlbaum Associates.

Silins, H. C., Mulford, W. R., \& Zarins, S. (2002). Organizational learning and school change. Educational Administration Quarterly, 38(5), 613-642.

Stoll, L. (2009). Capacity building for school improvement or creating capacity for learning? A changing landscape. Journal of Educational Change, 10(2-3), 115-127.

Strodl, P. (1988). Ethnic differences in dealing with experiences in multiethnic middle schools. Paper presented at the Urban Educational Research Conference, Brooklyn, NY. (ERIC Document No. ED 297 044)

Sung, S. Y., \& Choi, J. N. (2014). Do organizations spend wisely on employees? Effects of training and development investments on learning and innovation in organizations. Journal of Organizational Behavior, 35(3), 393-412. Doi. 10.1002/job.1897.

Sümer, N. (2000). Yapısal eşitlik modelleri: Temel kavramlar ve örnek uygulamalar. Türk Psikoloji Yazıları, 3(6), 49-74.

Sweetland, S. R., \& Hoy, W. K. (2000). School characteristics and educational outcomes: Toward an organizational model of student achievement in middle schools. Educational Administration Quarterly, 36(5), 703-729. Doi. $10.1177 / 00131610021969173$.

Şencan, H. (2005). Sosyal ve davranışsal ölçümlerde güvenirlik ve geçerlilik. Ankara: Seçkin Yayıncılık. 
Şentürk, H. E., ve Mutlu, T. O. (2019). An investigation on learning climate at sport high schools. Journal of Education and Training Studies, 7(9), 90-96.

Şişman, M. (2011). Ĕ̌gitimde mükemmellik arayışı: Etkili okullar. Ankara. Pegem Akademi Tabachnick, B. G. \& Fidell, L. S. (2007). Using multivariate statistics. Boston: Pearson. Tavşancıl, E (2006). Tutumların ölçülmesi ve SPSS ile veri analizi. Ankara: Nobel Yayın Tezbaşaran, A. (2008). Likert tipi ölçek hazırlama kılavuzu. Üçüncü Sürüm E-Kitap. [https://www.academia.edu/1288035/Likert_Tipi_Ölçek_Hazırlama_Kılavuzu], Erişim tarihi: 20.05.2020.

Vermeulen, M., Kreijns, K., Van Buuren, H., \& Van Acker, F. (2017). The role of transformative leadership, ICT-infrastructure and learning climate in teachers' use of digital learning materials during their classes. British Journal of educational technology, 48(6), 1427-1440. Doi.10.1111/bjet.12478.

Villegas-Reimers, E. (2003). Teacher professional development: An international review of the literature. UNESCO: International Institute for Education Planning, Paris.

Wang, M. L. (2012). How does the learning climate affect customer satisfaction? The Service Industries Journal, 32(8), 1283-1303.

Wang, M. T., \& Degol, J. L. (2016). School climate: A review of the construct, measurement, and impact on student outcomes. Educational Psychology Review, 28(2), 315-352.

Yıldırım, A., ve Şimşek, H. (2008). Sosyal bilimlerde nitel araştırma yöntemleri. Ankara: Seçkin.

Yielding, A. C. (1993). Interface between educational facilities and learning climate in three northern Alabama K-2 elementary schools, Unpublished doctoral dissertation, University of Alabama.

Yurdugül, H. (2005). Ölçek geliştirme çalışmalarında kapsam geçerliği için kapsam geçerlik indekslerinin kullanılması. XIV Ulusal Ĕgitim Bilimleri Kongresi Pamukkale, 1, 771774. 


\title{
Development of Learning Climate in Schools Scale (LCSS): Validity And Reliability Study*
}

\author{
Gökhan SAVAŞ**, Nihan DEMIRKASIMOĞLU***
}

- Received: 17.08.2020 • Accepted: 08.11.2020 • Online First: 01.12.2020

\begin{abstract}
Creating a climate that supports learning in schools is pivotal for enhancing student achievement by developing teacher competencies. This study aims to develop a valid and reliable scale that could be used to measure teachers' perceptions of school learning climate. In this study, firstly, an item pool, was created based on the literature and interviews with teachers. The draft form was then created and presented to experts from the fields of Educational Administration and Measurement and Evaluation to evaluate content validity. Data was collected from two different study groups consisting of 589 teachers employed in 18 elementary, 20 secondary, and 15 high schools. In the data analysis process, item analysis, exploratory factor analysis (EFA), first-order and second-order confirmatory factor analysis (CFA) was performed, and the reliability coefficient (Cronbach's alpha) was computed. Item analysis and EFA yielded a scale consisting of 22 items and four sub-scales. Sub-scales were named as a collaborative environment, principal support, school facilities, and professional interest. CFA revealed that the scale had acceptable fit indexes. Cronbach's alpha computed for determining internal consistency was .93 , which shows that the scale has high reliability. According to the results of validity and reliability analysis of the School Learning Climate Scale, it can be stated that it is a valid and reliable scale that can be used to measure teacher's perceptions of school learning climate. For further studies, it can be suggested to retest validity and reliability with the data to be gathered from private school teachers.
\end{abstract}

Keywords: climate, learning climate, school learning climate

\section{Cited:}

Savaş, G., \& Demirkasımoğlu, N. (2021). Development of learning climate in schools scale (LCSS): Validity and reliability study. Pamukkale University Journal of Education, 52, 147-178. doi:10.9779.pauefd.781446

\footnotetext{
* This study is a part of doctoral dissertation prepared by the $1^{\text {st }}$ author.

** Teacher, Republic of Turkey Ministry of National Education, ORCID ID: 0000-0003-0690-8733, gokhansavas37@gmail.com

*** Assoc. Prof. Dr., Hacettepe University Department of Educational Administration, ORCID ID: 0000-0001-8609-9985, nihansal@yahoo.com
} 


\section{Introduction}

In fast-changing, complicated, and diversified working environments, employees need to develop their competencies to keep up with current conditions. According to Nikolova et al. (2014), organizations' survival depends on creating encouraging environments for learning. Providing a learning environment in which employees can improve their competencies and share with their colleagues is an effective way of accomplishing organizational goals (Marsick \& Watkins, 2003). Employees' beliefs and attitudes towards learning are based on work context features such as creativity, innovation, supporting professional development, and administrative practices (Bates \& Khasawneh, 2005). Besides motivation and learning skills, employees' perceptions of the work environment also affect their learning (Atwal, 2013). It is asserted that these individual perceptions of the workplace are examined under the name of "climate" and are determinant upon creativity, learning, and performance (Hetland et al., 2011; Rousseau, 1988). These views saliently yield to highlight the need to create a positive learning climate to accomplish learning effectively.

In the existing literature, different terms have been used for implying learning conditions of organizations such as "learning climate" (Atwal, 2013; Bowen \& Kilmann, 1975; Bozdoğan \& Sağnak 2011; Cherkowski, 2016; Eldor \& Harpaz, 2016; Hallinger, Bickman \& Davis, 1996; O’Donnell \& White, 2005; Shoshani \& Eldor, 2016; Yielding, 1993), "learning culture" (Bates \& Khasawneh, 2005; Koops \& Winsor, 2006; Lu et al., 2015; Masitsa, 2005; Oluremi, 2008), “academic climate” (Wang \& Degol, 2016), "learning orientation" (Opfer, Pedder \& Lavicza, 2011), "learning atmosphere" (Pan, 2004) and "learning environment (Stoll, 2009). Culture reflects more abstract terms like beliefs and values, while climate includes more observable and measurable workplace characteristics (Schein, 1990; Wang, 2012). Climate refers to individual expectations, perceptions, and interpretations of organizational context that affect their behaviors. (Denison, 1996). School climate is specifically related to the school context for teaching and learning (Johnson \& Johson, 1999). It reflects what school administrators and teachers feel about their schools' features (Kaplan \& Geoffroy, 1990). In this study, the term "school learning climate" has been used as it implies more salient features of learning in schools.

In recent years, learning climate has received wide scholarly attention as an essential factor in enhancing teacher effectiveness (Eldor \& Harpaz, 2016). Furthermore, creating a climate that supports learning is seen as an effective way of promoting the employees' 
professional growth (Nikolova et al., 2014). Furthermore, the existing literature revealed the empirical link between learning climate and teacher professional learning (Atwal, 2013, Opfer, Pedder \& Lavicza, 2011), learning capacity (Prieto \& Revilla, 2006), willingness to use digital learning materials (Vermeulen et al., 2017), job satisfaction and motivation (Shoshani \& Eldor, 2016), innovative behaviors (Sung \& Choi, 2014), student learning (Bowen \& Kilmann, 1975; Moreland, 1984). A growing body of research has debated that organizational conditions can be a supportive or hindering factor for learning (Cortini, 2016; Nikolova et al., 2014). Learning climate as a vital component of teacher learning is seen as an environment consisting of various opportunities and activities through which teachers acquire, share, and learn knowledge (Shoshani \& Eldor, 2016). Learning climate as an organizational factor plays a crucial role in reaching formal and informal professional learning opportunities (Atwal, 2013). In schools with a positive learning climate, all school members solve educational problems and take responsibility for a common goal. Teachers who perceive a positive learning climate feel more valued and show more willingness to participate in learning activities (Şişman, 2011). A positive learning climate contributes to teachers' using alternative teaching practices and reflecting on experiences by arousing feelings of success and satisfaction (Shoshani \& Eldor, 2016). Furthermore, a positive learning climate is seen as a pivotal factor in enhancing teachers' professional competencies (Deal \& Peterson, 1999).

Since improving, teacher quality by supporting teacher learning is vital for schools to enhance both teacher and student performance (Hodkinson \& Hodkinson, 2005; Shoshani \& Eldor, 2016), developing teacher capacity and increasing their professional competencies has become the focal point of educational policies (Villegas-Reimers, 2003). Norms, patterns, and practices of schools can be a supporting or hindering factor for teacher learning. Schools that provide continuous learning opportunities, fostering research, dialogue, cooperation, and teamwork, and create a system in which leadership is distributed highly contribute to teacher learning (Opfer, Pedder \& Lavicza, 2011). In teacher learning, which is an interactive and continuous exchange of knowledge and experience, school and classroom are the settings where learning occurs (Liu, Hallinger \& Feng, 2016). Effective schools support teachers and provide a positive atmosphere for learning (Schunk \& Pajares, 2009). However, teachers who do not have supportive learning conditions in their schools can have difficulties in learning new things and transferring them to their teaching practices (Hollingsworth, 1999). 
Learning climate is claimed to have gained little scholarly attention due to the lack of valid and appropriate scales (Nikolova et al., 2014). As for Turkey, it is seen in the existing literature that scales adapted from different languages and cultures are used for measuring the learning climate. In some studies, the "Learning Climate Survey" developed by Tennessee School Safety Center and Lincoln Schools were used (Bora, 2010; Çamur, 2006; Şentürk \& Mutlu, 2019). In another study, Bozdoğan (2010) used "The Learning Climate Inventory" developed by Hoyle (1972) by adapting it into Turkish. Considering every country has a different educational system and cultural construct, a valid and reliable scale for measuring teachers' perceptions of learning climate in schools appropriately developed for Turkish culture is required.

In the existing literature, it is seen that studies on learning climate in schools mostly aimed to measure perceptions of the students (Bama, 1999; Damico \& Roth, 1993; Gerold \& Barnes, 1986; Kanadlı \& Bağçeci, 2016; Strodl, 1988). According to Social Cognitive Theory, separate roles of students and teachers have led to differentiation in their school context perceptions (Bandura, 1991). The school climate components, which seem less meaningless for students, can have a substantial effect on teachers' perceptions. These perceptions affect teachers' decisions on teaching (Perry \& Rahim, 2011). In this regard, it seems essential to develop new scales to measure teachers' perceptions of school climate (Liu et al., 2014).

Meanwhile, though the related literature includes tools measuring learning climate out of educational organizations (Eldor \& Harpaz, 2016; Bates \& Khasawneh, 2005; Nikolova et al., 2014), there is a limited number of scales measuring school climate-related to teacher learning (Shoshani \& Eldor, 2016). Besides, although school learning community scales are also used for investigating the school context of teacher learning, some dimensions of these scales are not appropriate for the Turkish educational system. It is, therefore, suggested that new measurement instruments should be developed by considering the cultural structure and codes of the Turkish educational system (Öğdem, 2015). Developing teacher learning requires defining features of the learning climate in schools. It is hypothesized that developing a valid and reliable scale for measuring teacher learning climate will be beneficial both theoretically and practically. Furthermore, this study's learning climate scale is thought to contribute to the existing literature by enabling investigation and improvement of learning climate in schools. 


\section{Learning Climate}

Learning climate is a relatively more recent concept emerged as a result of research on effective schools and focusing specifically on learning that separates it from the terms of school climate and organizational climate (Resendiz, 1994). During the period of restructuring of schools, the learning organization approach was a pivotal factor for the emergence of the learning climate (Çamur, 2016). Furthermore, the relationship of learning climate with learning quality and organizational performance made the term more widely accepted (Mikkelsen \& Grønhaug, 1999). According to Marsick and Watkins (2003), learning climate refers to employees' perceptions of beneficial organizational activities that enable them to generate, learn, and transfer knowledge. Lowe (1990) defined learning climate as feelings and perceptions of individuals towards physical and psychological variables that enable a positive learning atmosphere. According to Honey and Mumford (1996), the learning climate is an environment where behaviors and practices towards professional development are supported. Nikolova et al. (2014) described learning climate as employees' perceptions of organizational policies and practices that develop, reward, and enhance their learning behaviors. Similary, Eldor, and Harpaz (2016) stated that learning climate is a concept that reflects perceptions of employees of the degree to which the atmosphere of the organization encourages learning.

Lezotte et al. (1980) stated that the learning climate in schools has a distinctive meaning. By combining the terms "school" and "learning climate," an atmosphere comprised of ongoing learning practices in schools is underlined. A positive school climate that facilitates learning and teaching is a crucial component of learning culture in schools. In schools with a positive learning climate, teachers collaborate with their colleagues and school administrators, respect, and trust each other (Ellis, 1988). Silins, Mulford, and Zarins (2002) illustrated that in schools with a positive learning environment, leadership is distributed among school members, collaboration is encouraged, and teachers' learning needs are fulfilled. Kaplan and Geoffroy (1990) claimed that a positive learning climate helps teachers take more responsibility and risks for teaching by strengthening their sense of professional competency. Teachers in a supportive learning climate feel more effective, commit themselves to school goals, and trust their colleagues (Liu et al., 2014). A positive learning climate promotes communication among teachers, fosters their motivation, and makes them more effective in teaching (Yielding, 1993). When teachers perceive a 
supportive learning climate, they tend to take more responsibility for student learning, show a willingness to teach, and never give up against problems (Sweetland \& Hoy, 2000).

\section{Dimensions and Measurement of Learning Climate in Schools}

One of the pioneering research on learning climate in schools was conducted by Hoyle (1972), who developed "The Learning Climate Inventory" to determine teachers' perceptions of learning climate. The scale consisted of five sub-dimensions as leadership, freedom, evaluation, compliance, and cooperation. Moreland (1984) developed "The School Learning Climate Assessment Instrument" for investigating teachers' perceptions of the learning climate. In this research, schools' learning climate was dimensioned as instructional leadership, academic emphasis, safe environment, expectations/evaluation, and test usage. Similarly, "Learning Climate Questionarrie" developed by Bartram et al. (1993) involved seven dimensions as management style, time, autonomy and responsibility, team style, opportunities to develop, guidelines, and satisfaction. Another scale used to measure schools' learning climate is the "Learning Organization Questionnaire" developed by Marsick and Watkins (2003). It was used in several studies to investigate schools' learning climate (Eldor \& Harpaz, 2016; Shoshani \& Eldor, 2016). The scale has a single structure construct involving items related to continuous learning, inquiry, dialogue, team learning, collective vision, and strategic leadership. Aldridge, Laugksch, and Fraser (2006) developed the "School Level Environment Questionnaire" to assess teachers' perceptions of the schoollevel environment. The measurement instrument involved seven dimensions: parental involvement, student support, collegiality, familiarity, innovation, resource adequacy, and work pressure. Nikolova et al. (2014) developed the "Learning Climate Scale" to measure employees' perceptions of organizations' learning climate. The scale involved three factors as facilitation climate, appreciation climate, and error avoidance climate. Another scale that is used widely in the literature is the "Learning Climate Survey" developed by Tennessee School Safety Center and Lincoln Schools. The scale includes dimensions related to safety, facilities, sources and environment, participation in decision making, student management, curriculum, teaching, success, and morale.

In the existing literature, it is seen that the learning climate in schools includes various sub-dimensions. However, definitions and findings from several studies explicitly revealed that the learning climate involves some common points. These common factors are collaboration, sharing, sources, personal characteristics, and a common vision. Highlighted common dimensions served as a guideline for this research in developing a scale for 
measuring the learning climate in schools required for effective teacher learning. The dimensions of the scale developed in this study were regarded to be consistent with the dimensions revealed in previous studies in the literature. As many of the earlier scales of learning climate were not developed for measuring perceptions of teachers, teacher views were also used in the process of item preparation.

\section{Method}

Research data were gathered under the permission of the Hacettepe Üniversitesi Ethics Commission granted on $09^{\text {th }}$ June 2020 with document number 35853172-600. This study, which aimed to develop a valid and reliable scale for measuring teachers' perceptions of learning climate, was conducted through a descriptive scanning model. A descriptive model is a research approach that aims to describe a previous or recent existing condition as it is (Karasar, 1999). In the following part, information on study groups and the data collection process is presented.

\section{Participants}

Within this study, data were collected from two separate study groups. The study groups consisted of volunteer teachers employed in state elementary, secondary, and high schools in the spring term in 2020. In determining the sample, the convenience sampling method was used. The convenience sampling method is claimed to provide the researcher pace and practicality since the researcher prefers a situation that is closer and more accessible (Yıldırım \& Şimşek, 2008). Exploratory Factor Analysis (EFA) was performed with the online data gathered from the first study group consisting of 279 teachers, and CFA was performed with the data gathered from the first study group consisting of 310 teachers. The sample size is claimed to be essential for strong factor analysis (Tabachnik \& Fidell, 2007). In the existing literature, there are various views related to the sample size required for factor analysis. For example, Kline (1994) stated that the required sample size for factor analysis should be at least 100 , but greater would yield more good results. According to Comrey and Lee (1992), 200 participants are average, and 300 participants are good sample size for factor analysis. Cattell (1978) asserted that a sample size from three to six times the item number or approximately 250 is sufficient for factor analysis. According to Tavşancil (2006), the sample size should be at least five times the item number for strong factor analysis. Considering the suggested standards in the literature, it can be stated that the 
sample size is sufficient for performing factor analysis in this study. Demographic data related to the study groups are given in Table 1.

Table 1. Demographical characteristics of the participants

\begin{tabular}{|c|c|c|c|c|c|}
\hline \multicolumn{2}{|c|}{ Variable } & \multicolumn{2}{|c|}{ First study group } & \multicolumn{2}{|c|}{ Second study group } \\
\hline & & $f$ & $\%$ & $f$ & $\%$ \\
\hline \multirow{2}{*}{ Gender } & Female & 166 & 59,5 & 174 & 56,1 \\
\hline & Male & 113 & 40,5 & 136 & 43,9 \\
\hline \multirow{3}{*}{ School Level } & Elementary School & 101 & 36,2 & 115 & 37,1 \\
\hline & Secondary School & 100 & 35,8 & 150 & 48,4 \\
\hline & High School & 78 & 28,0 & 45 & 14,5 \\
\hline \multirow{5}{*}{$\begin{array}{l}\text { Years of } \\
\text { experience }\end{array}$} & $1-5$ years & 38 & 13,6 & 47 & 15,2 \\
\hline & $6-10$ years & 60 & 21,5 & 64 & 20,6 \\
\hline & $11-15$ years & 86 & 30,8 & 83 & 26,8 \\
\hline & $16-20$ years & 49 & 17,6 & 61 & 19,7 \\
\hline & 20 years and over & 46 & 16,5 & 55 & 17,7 \\
\hline \multirow{3}{*}{$\begin{array}{l}\text { Educational } \\
\text { Level }\end{array}$} & Undergraduate & 215 & 77,1 & 267 & 86,1 \\
\hline & Graduate & 64 & 22,9 & 43 & 13,9 \\
\hline & Total & 279 & 100,0 & 310 & 100 \\
\hline
\end{tabular}

When Table 1 is examined, it can be seen that of the participants in the first study group \%59.5 $(\mathrm{n}=166)$ were females and \%40.5 $(\mathrm{n}=113)$ were males. Of the participants in the first study group \%, $36.2(\mathrm{n}=101)$ were primary school teachers, \%35.8 $(\mathrm{n}=100)$ were secondary school teachers, and \%28 $(\mathrm{n}=78)$ were high school teachers. Distribution of teachers by years of experience shows that of the participants $\% 13.6(n=38)$ have 1 to 5 years, \%21.5 $(\mathrm{n}=60)$ have 6 to 10 years, \%30.8 $(\mathrm{n}=86)$ have 11 to 15 years, \%17.6 $(\mathrm{n}=49)$ have 16 to 20 years, and \%16.5 $(n=46)$ have 21 years and over teaching experience. Of the participants, \%77.1 $(\mathrm{n}=215)$ completed graduate and \%22.9 $\quad(\mathrm{n}=64)$ completed undergraduate education.

Of the participants in the second study group \%56.1 $(n=174)$ were females , \%43.9 $(n=136)$ were males. Of the participants in the second study group \%37.1 $(n=115)$ were primary school teachers, \%48.4 $(n=150)$ were secondary school teachers and \%14,5 $(n=45)$ were high school teachers. Distribution of teachers by years of experience indicates that of the participants $\% 15.2(\mathrm{n}=47)$ have 1 to 5 years, \%20.6 $(\mathrm{n}=64)$ have 6 to 10 years, \%26.8 
$(\mathrm{n}=83)$ have 11 to 15 years, \%19.7 $(\mathrm{n}=61)$ have 16 to 20 years and \%17.7 $(\mathrm{n}=55)$ have 21 years and over teaching experience. Of the participants \%86.1 $(\mathrm{n}=267)$ completed graduate and \%13.9 $(\mathrm{n}=43)$ completed undergraduate education.

\section{The Process of Scale Development}

In the process of determining items, deductive and inductive methods were used in combination. In the deductive approach, items of the scale are determined as a result of a detailed analysis of the existing literature. In the inductive approach, items are determined after interviews with a group defined in the target population (Hinkin, 1995). Within the scope of this study, the existing literature related to the learning climate was scrutinized. Scales of learning climate developed by Nikolova et al. (2014), Opfer, Pedder, and Lavicza (2011), Bartram et al. (1993), and Hoyle (1972) were also examined. Furthermore, a total of 12 teachers were interviewed to evaluate their views on the learning climate. As a result of the literature review and interviews with teachers, an item pool consisting of 35 items was created. The scales were thought to be represented under four dimensions: principal support, collaborative environment, school facilities, and professional support. For example, items were stated as "School principals encourage teachers to learn new things" in the principal support dimension; "Teachers share their professional knowledge and experience" in the collaborative environment dimension; "Teachers own necessary sources (books, magazines, and internet) for professional learning" in school facilities dimension and "Teachers follow recent developments in their fields" in professional interest dimension. To determine the degree of frequency, the statements were designed as a 5-point Likert-type scaling ranging from $1=$ Never to $5=$ Always.

Items of the scale are required to be sufficient in reflecting the intended behaviors. Accordingly, one of the methods for evaluating content validity is appealing for expert opinions (Büyüköztürk et al., 2016). Expert opinions should be benefitted for determining whether items under each factor represents behaviors in that factor in multi-dimensional measurement instruments (DeVellis, 2003). Therefore, the items were presented to 13 field experts, 12 of them are employed in Educational Administration, and one is in Measurement and Evaluation Departments. Expert opinions were collected through a form consisting of options as "Essential," "Partially essential," and "Remove." Participants were requested to state their opinions for the items they evaluated as partially essential and not essential. Analysis of expert opinions was conducted via the Lawshe method. In this method, five to forty experts are required for determining content validity. By adding up the experts' 
responses related to each item, a content validity ratio (CVR) is obtained. The minimum CVR value is calculated as .54 for 13 experts (Yurdugül, 2005). In this study, therefore, CVR values were calculated for each item. Nine items below .54 were removed from the form. Besides, according to the suggestions of experts, statements of eight items were revised. To evaluate the items in terms of suitability for language, two Turkish language teachers were consulted. As a result of experts' evaluation in terms of spelling rules, expression, and punctuation, items of the scale were re-examined. Furthermore, 10 teachers out of the study groups were asked to evaluate the comprehensibility of the items. Regarding the feedbacks, the scale consisting of 26 items was made ready for application.

\section{Data Analysis}

Data were analyzed via SPSS 20 and AMOS 23 statistical programs. In the data analysis process, firstly, $\mathrm{Z}$ scores, and Mahalanobis distance values were calculated to arrange data for factor analysis. Item analysis was performed to investigate whether the data is relevant to the desired attitude and can discriminate different degrees (Tezbaşaran, 2008). The normality of the data was checked through the analysis of Skewness and Kurtosis values. To determine the multicollinearity between items of the scale, correlation coefficients $(r<.90)$ were examined (Tabachnick \& Fidell, 2007). Item discrimination was evaluated through item-total correlation and upper and lower \%27 group scores.

Exploratory Factor Analysis (EFA) was performed to examine the construct validity of the measurement instrument. EFA is an analysis used to determine factors based on the relationship between variables and used widely in studies of scale development (Büyüköztürk, 2012; Field, 2013). Principal Components Analysis (PCA) was used as a factor extraction method since it is claimed to be more effective in reducing factor uncertainty and psychometrically a more powerful method (Tabachnick \& Fidell, 2007). Direct Oblimin as one of the oblique factor rotation methods was preferred due to the correlations between factors (Çokluk, Şekercioğlu \& Büyüköztürk, 2010). Before EFA, Kaiser-Meyer Olkin (KMO) value was applied, and Bartlett's Sphericity test was performed to examine whether the data met the criteria for factor analysis. The factor structure was determined by considering an eigenvalue greater than one and scree-plot.

To confirm the four-factor structure that emerged from EFA, first order and second order Confirmatory Factor Analysis (CFA) were conducted. CFA is a factor analysis method used to test a structure or hypothesis of a previously emerged relationship (Field, 2013). The validity of the model was tested through Chi-Square Goodness of Fit test ( $\left.\chi^{2}\right)$, Goodness of 
Fit Index (GFI), Goodness of Fit Index (AGFI), Root Mean Square Error of Approximation (RMSEA), Comparative Fit Index (CFI) ve Normed Fit Goodness of Fit test ( $\chi 2)$, Goodness of Fit Index (GFI), Goodness of Fit Index (AGFI), Root Mean Square Error of Approximation (RMSEA), Comparative Fit Index (CFI) ve Normed Fit Index (NFI) values. Cronbach's alpha and correlation coefficients between factors were calculated for evaluating the reliability of the instrument.

\section{Findings}

This section presents findings related to item analysis, exploratory factor analysis, first and second-order confirmatory factor analysis, and reliability analysis.

\section{Item Analysis}

When examining Table 2, which displays the item analysis results for examining relevancy of the data with the desired attitude and discriminability of the items, it is seen that arithmetic means of the items varied between 2.78 and 3.96. Considering Skewness and Kurtosis values, it was found that item 12 did not meet the univariate normality assumption. Skewness and Kurtosis values between \pm 1 exhibit that the data does not pose a significant deviation from normality (Çokluk, Şekercioğlu \& Büyüköztürk, 2010). It is suggested that items deviating from these values can be excluded from the instrument in the scale development process (Şencan, 2005). Item 12 was, therefore, removed from the instrument. Skewness and Kurtosis values of the remaining items were found to vary between .037 and .953. These values prove the normal distribution of the research data.

Positive and higher item-total correlation values indicate that an instrument's items illustrate similar properties, and internal consistency is higher. In Likert-type scales, items that exhibit lower relationships with the total score are suggested to be removed from the scale (Tezbaşaran, 2008). Items having above .30 item-total correlation is stated to be sufficiently discriminable (Büyüköztürk, 2012). Therefore, item 10 was removed from the scale as it had a below 30 item-total correlation value. The analysis was re-performed after excluding these items, and the remaining items were calculated to range between .47 and .69. Lastly, $\mathrm{t}$ values regarding the differences between upper and lower \%27 group scores were found to vary between 8.06 and 15.89 and significantly differed in $\mathrm{p}<.05$ level. According to these findings, it can be stated that each item in the scale is sufficiently discriminable. 
Table 2. Results of Item Analysis

\begin{tabular}{|c|c|c|c|c|c|c|c|}
\hline \multirow[t]{3}{*}{$\begin{array}{c}\text { Item } \\
\text { Number }\end{array}$} & \multirow[t]{3}{*}{ Mean } & \multirow[t]{3}{*}{ S.D. } & \multirow[t]{3}{*}{ Skewness } & \multirow[t]{3}{*}{ Kurtosis } & \multicolumn{2}{|c|}{$\begin{array}{l}\text { Corrected Item- } \\
\text { Total Correlation }{ }^{1}\end{array}$} & \multirow{3}{*}{$\begin{array}{c}\text { Upper and } \\
\text { Lower \%27 Item } \\
\text { Discrimination } \\
\text { Index }^{2}\end{array}$} \\
\hline & & & & & $1^{\text {st }}$ level & $2^{\text {nd }}$ level & \\
\hline & & & & & & & \\
\hline 1 & 3,50 & 1,134 &,- 421 &,- 701 & ,577 & ,592 & $12,267^{* * *}$ \\
\hline 2 & 3,50 & 1,166 &,- 444 &,- 650 & ,683 & ,696 & $14,607^{\text {*** }}$ \\
\hline 3 & 3,76 & 1,148 &,- 647 &,- 539 & ,659 & ,670 & $15,136^{* * *}$ \\
\hline 4 & 3,75 & 1,046 &,- 583 &,- 247 & ,617 & ,626 & $14,254^{* * * *}$ \\
\hline 5 & 3,28 & 1,083 &,- 370 &,- 335 & ,639 & ,653 & $14,314^{* * *}$ \\
\hline 6 & 3,88 & 1,073 &,- 830 & ,037 & ,625 & ,626 & $13,932^{* * *}$ \\
\hline 7 & 3,86 & 1,095 &,- 778 &,- 158 & ,627 & ,633 & $14,540^{* * *}$ \\
\hline 8 & 3,80 & ,916 &,- 177 &,- 908 &, 562 &, 547 & $10,650^{* * *}$ \\
\hline 9 & 3,72 & ,843 &,- 238 &,- 508 & ,572 &, 560 & $10,841^{* * *}$ \\
\hline 10 & 2,78 & ,951 & ,248 &,- 217 & ,236 & & $3,296^{* * * *}$ \\
\hline 11 & 3,37 & ,942 & ,016 &,- 495 & ,488 & ,480 & $8,683^{* * *}$ \\
\hline 12 & 3,96 &, 843 &,- 911 & 1,293 &, 533 & & $8,717^{* * *}$ \\
\hline 13 & 3,60 & ,883 &,- 045 &,- 723 & ,616 & ,604 & $10,505^{* * *}$ \\
\hline 14 & 3,30 & ,829 &,- 124 &,- 233 & ,546 &, 540 & $8,063^{* * *}$ \\
\hline 15 & 3,70 & ,931 &,- 472 &,- 236 & ,647 & ,640 & $13,663^{* * *}$ \\
\hline 16 & 3,81 & ,872 &,- 366 &,- 354 &, 568 &, 554 & $11,573^{* * *}$ \\
\hline 17 & 3,53 & ,940 &,- 246 &,- 398 & ,689 & ,676 & $15,889^{* * *}$ \\
\hline 18 & 3,76 & ,878 &,- 290 &,- 598 & ,699 & ,692 & $14,765^{* * *}$ \\
\hline 19 & 3,81 & ,846 &,- 381 &,- 211 & ,670 & ,654 & $12,164^{* * *}$ \\
\hline 20 & 3,57 & ,853 &,- 459 & ,030 & ,615 & ,615 & $11,260^{* * *}$ \\
\hline 21 & 3,12 & ,995 &, 025 &,- 553 & ,562 &, 564 & $9,892^{* * * *}$ \\
\hline 22 & 3,96 & ,786 &,- 564 & ,129 & ,556 &, 554 & $9,157^{* * *}$ \\
\hline 23 & 3,86 & ,932 &,- 657 &, 027 &, 537 &, 538 & $9,245^{* * *}$ \\
\hline 24 & 3,43 & 1,100 &,- 246 &,- 732 &, 504 &, 502 & $9,390^{* * *}$ \\
\hline 25 & 3,49 & 1,000 &,- 508 &,- 269 &, 519 &, 529 & $9,486^{* * *}$ \\
\hline 26 & 3,40 & 1,201 &,- 303 &,- 953 & ,459 & ,471 & $9,461^{* * *}$ \\
\hline
\end{tabular}




\section{Exploratory Factor Analysis}

Firstly, Kaiser-Meyer Olkin (KMO) coefficient and Bartlett Sphericity test were used the determine whether the data set was suitable for factor analysis. KMO value was calculated as .93. Bartlett Sphericity test (Chi-square $=4502,72$; df $=276 ; \mathrm{p}<, 05)$ yielded significant result. KMO value greater than .60 and significant value of Bartlett Sphericity test indicates the suitability of the data set for factor analysis (Büyüköztürk, 2012; Field, 2013). According to these findings, it was seen that research data were suitable for factor analysis. Principal Components Analysis as a factor extracting method was used in EFA. The results of the analysis revealed that items of the scale were gathered under four factors, with an eigenvalue greater than one. Findings related to the factor structure of the scale were displayed in Table 3.

Table 3. Findings of Principal Components Analysis Related to Factor Structure Of The Scale

\begin{tabular}{lccc} 
Factor & Eigenvalue & Variance $(\%)$ & Total Variance $(\%)$ \\
\hline 1 & 9,760 & 40,67 & 40,67 \\
2 & 3,342 & 13,93 & 54,60 \\
3 & 1,749 & 7,29 & 61,88 \\
4 & 1,262 & 5,26 & 67,14 \\
\hline
\end{tabular}

In determining factor numbers, eigenvalue, variance rate, and scree-plot are seen as important indicators (Büyüköztürk, 2012; Çokluk, Şekercioğlu and Büyüköztürk, 2010). When the Table is examined, it is seen that four factors were extracted with an eigenvalue of 9.760, 3.342, 1.749, and 1.262, respectively. In factor analysis, factors having an eigenvalue greater than one are accepted as significant factors (Field, 2013). This finding of the study indicated that the scale consisted of four factors with an eigenvalue greater than one. Considering the findings related to explained variance, it was revealed that four factors explained $\% 67,14$ of the total variance $(\% 40,67, \% 13,93, \% 7,29$ and 5,26, respectively). Factor number that firstly explained $2 / 3$ of the total variance is seen as significant. Higher explained variance means a better measurement of the related structure (Büyüköztürk, 2012). This finding indicated that the total variance of LCS was sufficient. Scree plot graph used one of the important indicators in determining factor structure is given in Figure 1. 


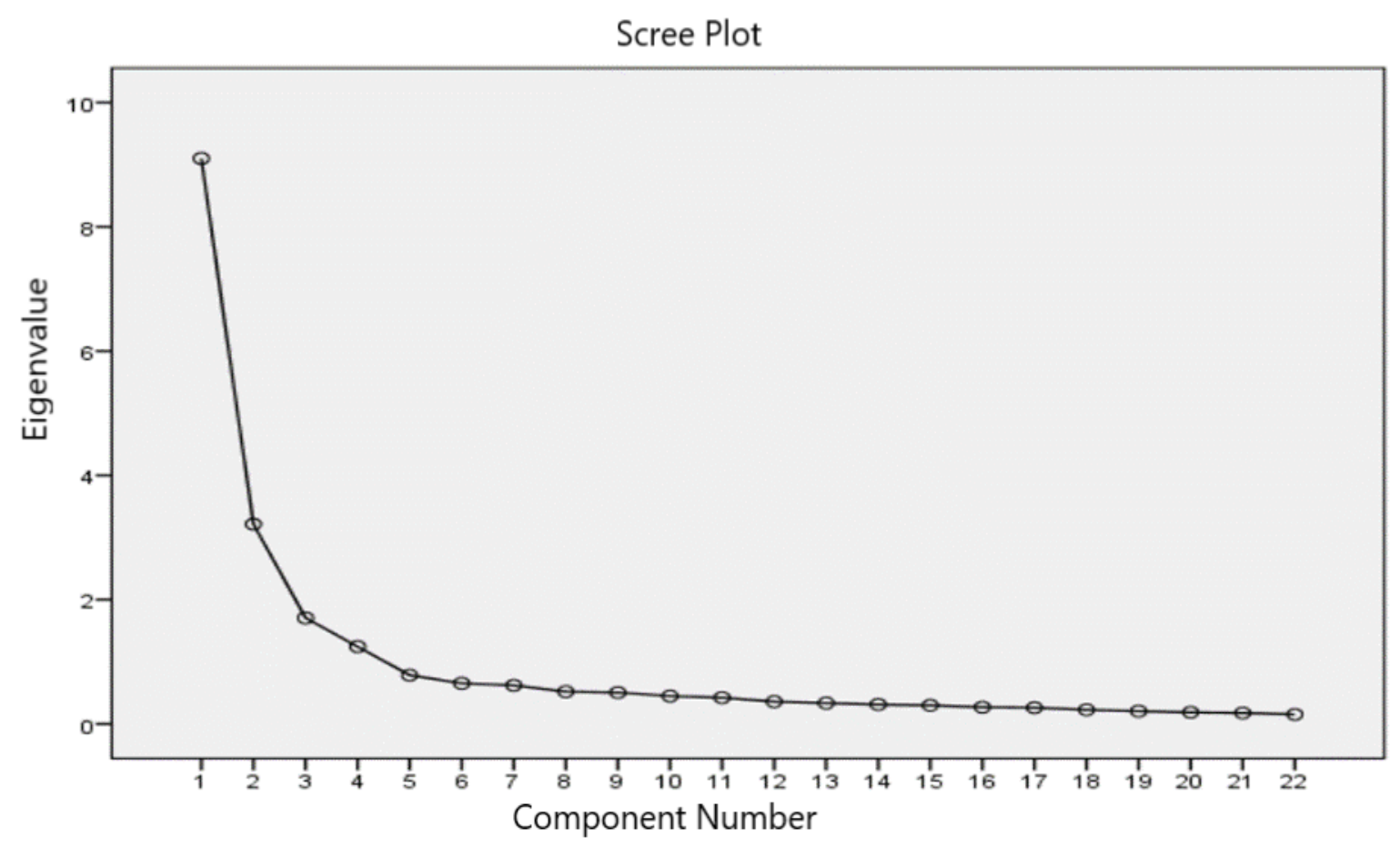

Figure 1. Scree Plot Related to the Factor Structure of LCS

In a scree plot graph, the space between each point from the top to the declining slope point shows implications about factor number. The point on which the slope begins to decline is the breaking point, and the contribution of factors to the variance decreases as of this point (Çokluk, Şekercioğlu, \& Büyüköztürk, 2010). When Figure 1 is examined, a decline in the slope is observed as of the fourth factor, and the graph begins to hold a horizontal structure. It can be, therefore, argued that the scale had a four-factor structure.

To determine the factors under which the items were gathered, Direct Oblimin as an oblique rotation technique was preferred since the factors were assumed to be associated with each other (Field, 2013). As a result of EFA, factor loadings and common factor variances are shown in Table 4. 
Table 4. Results of Exploratory Factor Analysis

\begin{tabular}{|c|c|c|c|c|c|c|c|}
\hline Item Number & $\begin{array}{l}\ddot{0} \\
\stackrel{0}{0} \\
\tilde{E} \\
\tilde{I} \\
\tilde{n} \\
-\end{array}$ & 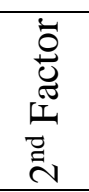 & $\begin{array}{l}\overline{0} \\
\stackrel{0}{0} \\
\tilde{E} \\
\bar{m} \\
\dot{m}\end{array}$ & 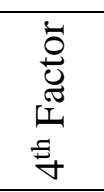 & 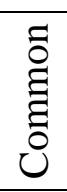 & 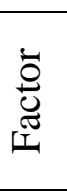 & 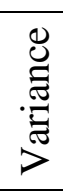 \\
\hline Item 20 & .806 & & & & & .68 & \\
\hline Item 18 & .778 & & & & & .62 & \\
\hline Item 15 & .777 & & & & & .61 & \\
\hline Item 19 & .765 & & & & & .61 & \\
\hline Item 16 & .764 & & & & & .59 & \\
\hline Item 17 & .743 & & & & & .58 & \\
\hline Item 1 & & .859 & & & & .75 & \\
\hline Item 4 & & .855 & & & & .74 & \\
\hline Item 7 & & .854 & & & & .76 & \\
\hline Item 3 & & .846 & & & & .73 & \\
\hline Item 6 & & .845 & & & & .76 & \\
\hline Item 2 & & .836 & & & & .72 & \\
\hline Item 5 & & .835 & & & & .73 & \\
\hline Item 25 & & & .846 & & & .72 & \\
\hline Item 23 & & & .813 & & & .66 & \\
\hline Item 24 & & & 699 & & & .53 & \\
\hline Item 26 & & & .655 & & & .47 & \\
\hline Item 22 & & & .650 & & & .44 & \\
\hline Item 8 & & & & .883 & & .78 & \\
\hline Item 9 & & & & .865 & & .75 & \\
\hline Item 11 & & & & .681 & & .49 & \\
\hline Item 13 & & & & .620 & & .46 & \\
\hline
\end{tabular}

It is argued that item factor loadings should be above .50 to ensure construct validity requirements (Fornell \& Larcker, 1981; Nunally, 1978). Therefore, .50 was specified as a lower limit of factor loadings. As a result of the analysis, the factor loadings of a few items were calculated to be lower than .50. For this reason, items 14 and 21 were removed from the scale, and the analysis was re-performed. No items were found to have high factor loadings in more than one factor. Besides factor loadings, common factor variances are also used in evaluating the findings of EFA. Common factor variances show the degree to which 
the extracted factors are jointly represented. Therefore, items having a common factor variance below .20 must be excluded from the instrument (Şencan, 2005). The analysis revealed that there were no items that have a common factor variance below .20 .

Consequently, when Table 4 is examined, it could be seen that factor loadings of the items varied between .620 and .859. Costello and Osborne (2005) stated that items with factor loadings above .50 have strong load values. It is also seen that all items sufficiently contribute to the common variance. Four dimensions obtained as a result of EFA were entitled considering the content of the items. Sub-dimensions and items within these subscales are displayed in Table 5.

Table 5. Sub-dimensions and related items determined as a result of EFA

\begin{tabular}{lcc}
\hline Sub-dimensions & $\begin{array}{c}\text { Number of } \\
\text { items }\end{array}$ & Items \\
\hline Collaborative Environment & 6 & $15,16,17,18,19,20$ \\
Principal Support & 7 & $1,2,3,4,5,6,7$ \\
School Facilitites & 5 & $22,23,24,25,26$ \\
Professional Interest & 4 & $8,9,11,13$ \\
\hline
\end{tabular}

When Table 5 is examined, six items $(15,16,17,18,19,20)$ under "Collaborative Environment", seven items $(1,2,3,4,5,6,7)$ under "Principal Support", five items $(22,23,24,25,26)$ under "School Facilitites" and four items $(8,9,11,13)$ under "Professional Interest" sub-dimensions.

\section{First Order Confirmatory Factor Analysis}

To validate the structure consisting of 22 items and four factors and test model-data fit, firstorder CFA was performed with the data gathered from 310 participants. As a result of the analysis, the $\mathrm{t}$ values of the variables were examined. In the literature, it is stated that $\mathrm{t}$ values greater than 1.96 and 2.56 are significant at .05 and .01 levels respectively, and items that are not significant should be removed from the scale (Çokluk, Şekercioğlu \& Büyüköztürk, 2010). For the existing four-factor model, $t$ values were found to vary between 9.34 and 18.86. This finding indicated that all items were significant at the .01 level and not required to be excluded from the scale. Afterward, fit indexes of LCS were examined. The findings of the first-order CFA are displayed in Table 6. 
Table 6. The Goodness of Fit Indexes of Learning Climate in Schools Scale As a Result of First Order CFA

\begin{tabular}{llllllllll}
\hline$\chi 2$ & df & $\chi 2 / \mathrm{df}$ & RMSEA & RMR & GFI & AGFI & CFI & NFI & TLI \\
\hline 434.24 & 203 & 2.14 & .06 & .05 & .89 & .86 & .95 & .91 & .94 \\
\hline
\end{tabular}

When Table 6 is examined, it is seen that Chi-square and degree of freedom values were calculated to be $\chi^{2}=434, \mathrm{df}=203$. When the values were rated, the result of $\chi 2 / \mathrm{df}=2.14$ was obtained. $\chi^{2} / \mathrm{df}$ value below 3 and 5 indicates perfects fit and medium-level fit, respectively (Jöreskog \& Sörbom, 1993). Therefore, it could be stated that the $\chi 2 / \mathrm{df}$ value estimated for this model was an indicator of a good model fit. RMSEA value, which is one of the widely used fit indexes in DFA, is claimed to imply a good fit below .05 value and an acceptable fit below .08 value (Browne \& Cudeck, 1993; Kline, 1994). RMSEA value calculated as .06 for this model was an indicator of adequate fit. RMR value represents a good fit and acceptable fit below .05 and .10, respectively. RMR value found to be .05 for this model indicated a good model fit (Hu \& Bentler, 1995). Other fit indexes of LCS were calculated as $\mathrm{CFI}=.95$, NFI=.91, TLI=.94, $\mathrm{GFI}=.89$ ve $\mathrm{AGFI}=.86$. For these fit indexes, values above .90 point to a good fit and above .95 point to a perfect fit (Çokluk, Şekercioğlu \& Büyüköztürk, 2010; Schumacker \& Lomax, 2004; Sümer, 2000). However, since GFI and AGFI values are affected by sample size, values above .85 are claimed to be acceptable in evaluating model fit (Anderson \& Gerbing, 1984; Bryant, Yarnold \& Grimm, 1996; Schermelleh-Engel \& Moosbrugger, 2003). In the light of such information in the existing literature, it can be stated that CFI values indicated a good fit; NFI, TLI, GFI, and AGFI values indicated an acceptable fit. The path diagram of the four-factor model and factor loadings obtained from CFA are shown in Figure 2.

When standardized coefficients are examined in Figure 2, it is seen that the correlation coefficients of variables vary between .42 and .75 . Factor loadings of the items were calculated between .72 and .86 for "Collaborative Environment," .80 and .88 for "Principal Support," .61 and .73 for "School Facilities," and .73 and .85 for "Professional Support" sub-dimensions. All items having factor loadings above .50 indicated that each item excellently represented the factor to which it belongs (Fornell \& Larcker, 1981). 


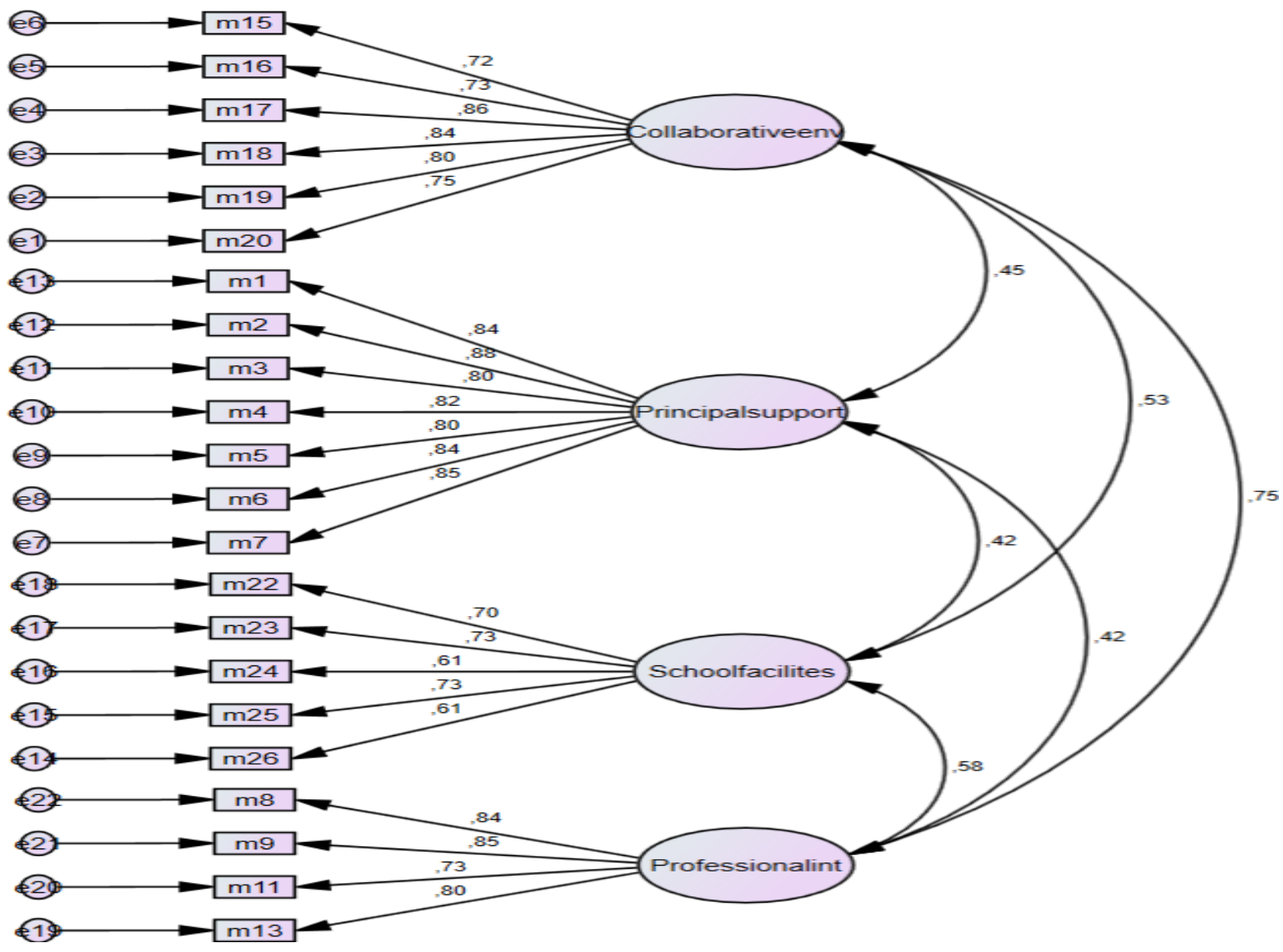

Figure 2. Results of First Order Confirmatory Analysis of Learning Climate in Schools Scale

\section{Second-Order Confirmatory Factor Analysis}

According to Meydan and Şeşen (2011), multi-factor scales should also be tested in terms of second-order multi-factor model fit. In this regard, second-order CFA was conducted to determine whether previously obtained four dimensions were converged under a more upper and inclusive factor, "Learning Climate." The goodness of fit indexes calculated as a result of second-order CFA performed by adding the second-order latent variable (learning climate) to the previously obtained model with four latent and 22 observed variables is given in Table 7.

Table 7. The Goodness of Fit Indexes of Learning Climate in Schools Scale As a Result of Second-Order CFA

\begin{tabular}{lccccccccc}
\hline$\chi 2$ & sd & $\chi 2 / s d$ & RMSEA & RMR & GFI & AGFI & CFI & NFI & TLI \\
\hline 439.26 & 205 & 2.14 & .06 & .05 & .88 & .86 & .95 & .91 & .94
\end{tabular}

When Table 7 is examined, it is seen that fit indexes were found as $\chi 2=439.26$ $(\mathrm{sd}=205, \mathrm{p}<.001),(\chi 2 / \mathrm{sd})=2.14, \mathrm{RMSEA}=.06, \mathrm{RMR}=.05, \mathrm{GFI}=.88, \mathrm{AGFI}=.86$, 
$\mathrm{CFI}=.95, \mathrm{NFI}=.91, \mathrm{TLI}=.94$ as a result of second order CFA. This finding indicates that four factor model shows good and acceptable fit (Anderson \& Gerbing, 1984; Jöroskog \& Sörbom, 1993; Kline, 1994; Schumacker \& Lomax, 2004). Path diagram which shows the factor-scale relation is displayed in Figure 3.

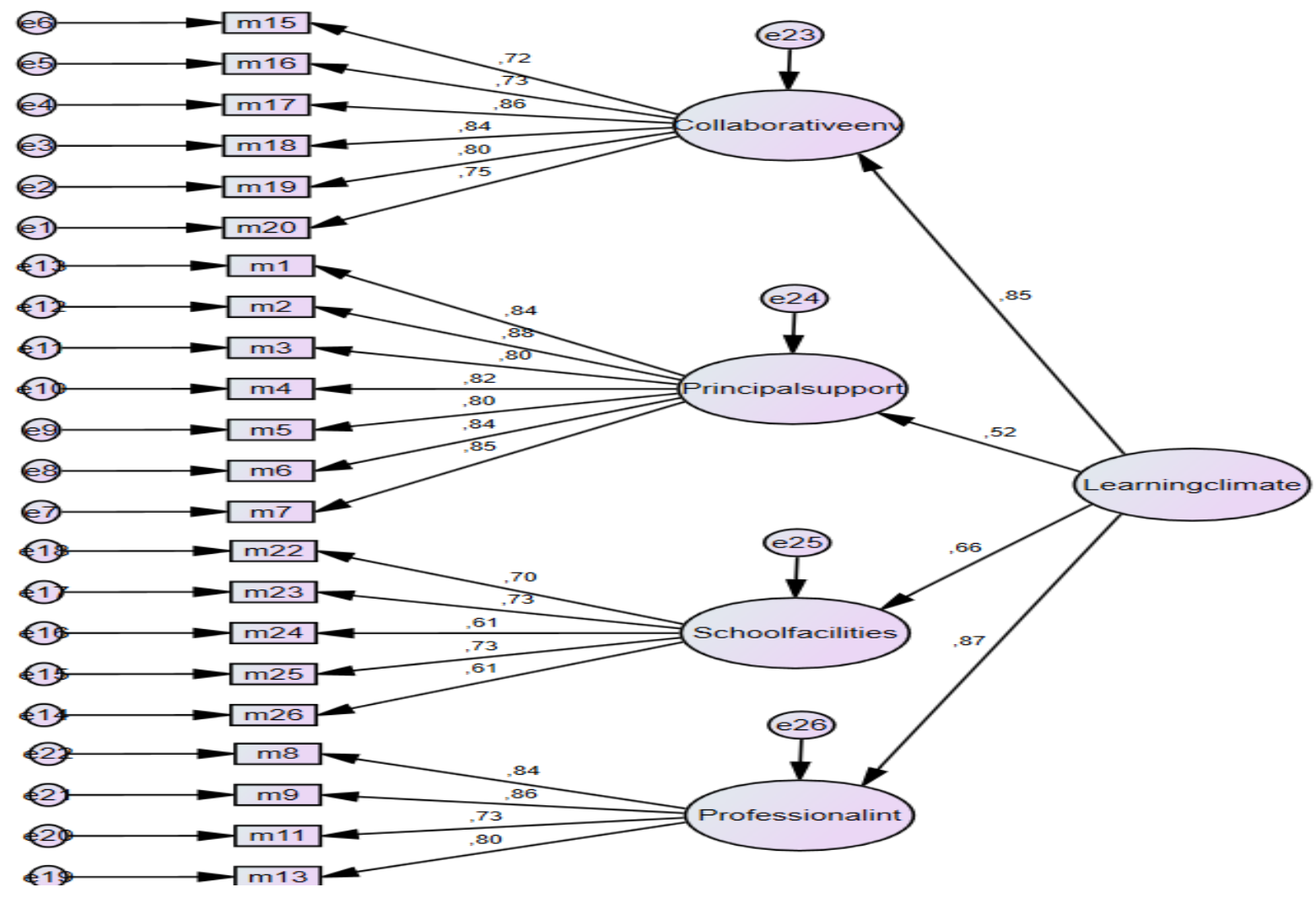

Figure 3. Results of Second-Order Confirmatory Analysis of Learning Climate in Schools

Scale

When Figure 3 is examined, it is seen that standardized coefficients varied between .52 and .87. Sub-scales that mostly explained "Learning Climate" were professional interest (.87), collaborative environment (.85), school facilities (.66), and principal support (.52). Furthermore, according to second-order CFA results, $t$ values were calculated to be 9.52 for a collaborative environment, 7.62 for principal support, 7.41 for school facilities, and 9.53 for professional interest sub-scales, which meant the result was significant at $p<.01$ level. The significance of the $\mathrm{T}$ value is an indicator of the model's acceptability (Schumacker \& Lomax, 2004). In the light of these findings, it can be concluded that LCS consisting of 22 items and four-factor is valid and has adequate goodness of fit. 


\section{Reliability Analysis}

According to Tezbaşaran (2008), internal consistency should be tested in Likert-type scales, and calculating Cronbach's Alpha method is the most appropriate way of testing reliability. For this reason, to determine the reliability level of the sub-dimensions and the whole LCS, Cronbach's Alpha coefficients were calculated (see Table 9).

Table 9. Cronbach's Alpha Correlation Coefficients of "Learning Climate in Schools Scale" and its Sub-dimensions

\begin{tabular}{lcc}
\hline Sub-dimensions & Number of items & Cronbach's Alpha \\
\hline Collaborative Environment & 6 & .91 \\
Principal Support & 7 & .94 \\
School Facilities & 5 & .80 \\
Professional Support & 4 & .86 \\
Learning Climate & 22 & .93 \\
\hline
\end{tabular}

When Table 9 is examined, it is seen that Cronbach's Alpha coefficients for subdimensions of LCS varied between .80 and .91. Cronbach's Alpha coefficient for the total scale was calculated as .93. Cronbach's Alpha value greater than .70 is claimed to be sufficient in terms of an instrument's reliability (Fraenkel \& Wallen, 2006; Nunnally, 1978; Şencan, 2005). It can be, therefore, stated that LCS is a reliable scale. Furthermore, correlations of sub-dimensions with each other and the total scale were evaluated to test the scale's internal consistency (see Table 10).

Table 10. Correlations between Sub-Dimensions and Total Scale

\begin{tabular}{lccccc}
\hline \multicolumn{1}{c}{ Components } & 1 & 2 & 3 & 4 & 5 \\
\hline 1-Collaborative & 1 & & & \\
Environment & & & & \\
2-Principal Support &, $427^{* *}$ & 1 & 1 & 1 & \\
3-School Facilities &, $506^{* *}$ &, $448^{* *}$ &, $314^{* *}$ &, $415^{* *}$ & \\
4-Professional &, $651^{* *}$ & & & & \\
Support &, $801^{* *}$ & 1 \\
5-Learning Climate &, $806^{* *}$ &, $841^{* *}$ & &
\end{tabular}


When Table 10 is examined, it is seen that correlation of sub-dimensions with each other, and the total scale was significant at $\mathrm{p}<0.01$ level. Correlation coefficients between the sub-dimensions of the scale varied between .31 and .65. In the literature, very high and low correlations between factors are not the desired situation (Çokluk, Şekercioğlu \& Büyüköztürk, 2010). Meanwhile, correlation coefficients below .80 indicate that the scale's discriminant validity is ensured (Brown, 2006). In the light of current findings, it can be concluded that positive and medium-level correlations between the sub-dimensions of the scale show that each sub-dimension measures different features. Furthermore, high and significant relationships were detected between sub-dimensions and total scale. This finding was another indicator of internal consistency and reliability of the scale.

\section{Discussion and Conclusion}

This research aimed to develop a valid and reliable scale that measures teachers' perceptions of the learning climate in schools. Accordingly, the existing literature related to learning climate was reviewed, and previous measurement tools of learning were investigated in detail (Bartram et al. 1993; Hoyle 1972; Nikolova et al. 2014, Opfer, Pedder \& Lavicza 2011). It was predicted that the scale could consist of four dimensions based on the existing literature. For testing validity, item analysis, exploratory factor analysis, first and secondorder confirmatory factor analysis were used, and reliability was tested through Cronbach's Alpha coefficients. EFA was performed with the online data gathered from the first study group consisting of 279 teachers, and CFA was performed with the data gathered from the first study group consisting of 310 teachers. As a result of the analysis, a scale consisting of 22 items and four factors were obtained. The four dimensions were entitled of a collaborative environment, principal support, school facilities, and professional support. The first-order and second-order DFA results determined whether the four sub-dimensions were combined under the upper learning climate factor indicated that the four-factor model is confirmed and has acceptable-level construct validity (Jöroskog \& Sörbom, 1993; Hu \& Bentler, 1995; Schumacker \& Lomax, 2004). In order to determine the reliability of the LCS, Cronbach's Alpha coefficients were calculated. Cronbach's Alpha coefficients were found as .93 for the scale as a whole, .91 for a collaborative environment, .94 for principal support, .80 for school facilities, and .86 for professional interest sub-dimensions. In this regard, it can be argued that LCS is a reliable measurement tool (Fraenkel \& Wallen, 2006). Lastly, correlations between the sub-dimensions were calculated between .31 and .65 . 
Correlation coefficients between the factors below .80 is an indicator of discriminant validity (Brown, 2006).

In conclusion, the results of the previously stated analyses revealed that LCS is a valid and reliable scale that can be used to measure teachers' perceptions of the learning climate in schools. The scale consisting of 22 items and four factors is a five-point Likerttype (from never to always) scale. The lowest and higher scores that can be received are 22 and 110, respectively. The increase in the received scores indicates the increase in teachers' perceptions levels of the existing learning climate in their schools. The scale developed within this study is thought to contribute to the research conducted to determine the characteristics of schools. It is suggested that the scale's validity and reliability should be tested in different samples, such as private school teachers.

\section{Limitations}

This research has some limitations. Firstly, the validity of the scale was tested through exploratory and confirmatory factor analysis. A criterion-based validity was not tested. This limitation can be removed in further studies. Secondly, data of the study were gathered from teachers employed at public schools. Considering the different learning facilities between state and private schools, this study can be a limitation not to include the characteristics of the learning climate in private schools. Therefore, it can be proper to re-test the validity and reliability of the data gathered from private school teachers in further studies.

Ethical Approval: This research was conducted under the permission of Hacettepe University Ethics Commission decided on 09.06.2020 with document number 35853172600.

Conflict Interest: There is no conflict of interest.

Authors Contributions: First author Gökhan SAVAŞ contributed to the study in the process of literature review, collecting data, analysis of the data and writing the article. Second author Assoc. Prof. Dr. Nihan DEMIRKASIMOĞLU contributed to the study in the process of creating the idea of the study, determining research method, writing and reviewing the article before submitting. 


\section{References}

Aldridge, J. M., Laugksch, R. C., \& Fraser, B. J. (2006). School-level environment and outcomes-based education in South Africa. Learning Environments Research, 9(2), 123-147.

Anderson, J.C., \& Gerbing D.W. (1984). The effect of sampling error on convergence, improper solutions, and goodness-of-fit indices for maximum likelihood confirmatory factor analysis. Psychometrika, 49, 155-173.

Atwal, K. (2013). Theories of workplace learning in relation to teacher professional learning in UK primary schools. Research in Teacher Education, 3(2), 22-27.

Bama, M. C. (1999). The relationship between students' perceptions of the school learning climate of a community of caring high school and selected characteristics of students and teachers. (Unpublished doctoral dissertation), Morgan State University, Maryland.

Bandura, A. (1991). Social cognitive theory. Organizational Behavior and Human Decision Processes, 50 (2), 248-287.

Bartram D., Foster J., Lindley PA., Brown AJ., \& Nixon S. (1993). Learning climate questionnaire (LCQ): Background and technical information. Oxford: Employment Service and Newland Park Associates Limited.

Bates, R., \& Khasawneh, S. (2005). Organizational learning culture, learning transfer climate and perceived innovation in Jordanian organizations. International Journal of Training and Development, 9(2), 96-109. Doi. 10.1111/j.1468-2419.2005.00224.

Bora, N. (2010). Uluslararası bakalorya diploma programının (IB) öğretmen ve ögrencilerin ögrenme iklimi ile ilgili algıları üzerindeki etkisi. Yayımlanmamış yüksek lisans tezi, Maltepe Üniversitesi, İstanbul.

Bowen, D. D., \& Kilmann, R. H. (1975). Developing a comparative measure of the learning climate in professional schools, Journal of Applied Psychology, 60, 71-79.

Bozdoğan, K. (2010) İlköğretim okulu müdürlerinin liderlik davranışlart ile okulun öğrenme ikliminin karşılaştırılması, Yayımlanmamış yüksek lisans tezi, Niğde Üniversitesi, Niğde. 
Bozdoğan, K. \& Sağnak, M. (2011). İlköğretim okulu müdürlerinin liderlik davranışları ile öğrenme iklimi arasındaki ilişki. Abant İzzet Baysal Üniversitesi Eğitim Fakültesi Dergisi, 11(1), 137-145.

Büyüköztürk, Ş. (2012). Sosyal bilimler için veri analizi el kitabı. Ankara: Pegem Akademi.

Büyüköztürk, Ş., Çakmak E., Akgün Ö., Karadeniz Ş. ve Demirel F. (2016). Bilimsel araştırma yöntemleri. Ankara: Pegem.

Bryant, F. B., Yarnold, P. R., \& Grimm, L. G. (1996). Toward a measurement model of the affect intensity measure: A three-factor structure. Journal of Research in Personality, 30(2), 223-247. Doi. 10.1006/jrpe.1996.0015.

Brown, T. A. (2006). Confirmatory factor analysis for applied research. New York, NY: Guilford Press.

Browne, M. W., \& Cudeck, R. (1993). Alternative ways of assessing model fit. In: K. A. Bollen\& J. S. Long (Eds.), Testing structural equation models (pp. 136-162). Beverly Hills, CA: Sage.

Cattell, R. B. (1978). The scientific use of factor analysis in behavioral and life sciences. New York: Plenum.

Cherkowski, S.6 (2016). Exploring the role of the school principal in cultivating a professional learning climate. Journal of School Leadership, 26(3), 523-543. Doi. $10.1177 / 105268461602600306$

Comrey, A., \& Lee, H. (1992). Interpretation and application of factor analytic results. In A. Comrey, \& H. Lee (Eds.), A first course in factor analysis. USA: Psychology Press, New York.

Cortini, M. (2016). Workplace identity as a mediator in the relationship between learning climate and job satisfaction during apprenticeship: suggestions for HR practitioners, Journal of Workplace Learning, 28(2), 54-65. Doi. 10.1108/JWL-12-2015-0093.

Costello, A., \& Osborne, J. (2005). Best practices in exploratory factor analysis: Four recommendations for getting the most from your analysis. Practical Assessment, Research And Evaluation, 10 (7), 1-9.

Çamur, A. (2006). Liselerde ögrrenme iklimine ilişkin yönetici, ögrretmen, veli ve öğrenci görüşleri, Yayımlanmamış yüksek lisans tezi, Ege Üniversitesi, İzmir. 
Çokluk, Ö., Şekercioğlu, G. \& Büyüköztürk, Ş. (2010). Sosyal bilimler için çok değişkenli istatistik: SPSS ve LISREL uygulamalart. Ankara: Pegem.

Damico, S. B., \& Roth, J. (1993). General Track Students' Perceptions of School Policies and Practices. Journal of Research and Development in Education, 27(1), 1-8.

Deal, T. E., \& Peterson, K. D. (1999). Shaping school culture: The heart of leadership. San Francisco, CA: Jossey-Bass.

Denison, D. R. (1996). What is the difference between organizational culture and organizational climate? A native's point of view on a decade of paradigm wars. Academy of Management Review, 21(3), 619-654.

DeVellis, R. F. (2003). Scale development: Theory and applications. Newbury Park: Sage Publications.

Eldor, L., \& Harpaz, I. (2016). A process model of employee engagement: The learning climate and its relationship with extra-role performance behaviors. Journal of Organizational Behavior, 37(2), 213-235. Doi.10.1002/job.2037.

Ellis, R. J. (1988). Self-monitoring and leadership emergence in groups. Personality and Social Psychology Bulletin, 14(4), 681-693. Doi. 10.1177/0146167288144004.

Field, A. (2013). Discovering statistics using IBM SPSS statistics (4th ed.). London: Sage.

Fornell, C., \& Larcker, D. F. (1981). Evaluating structural equation models with unobservable variables and measurement error. Journal of Marketing Research, 18(1), 39-50.

Fraenkel, J.R., \& Wallen, N.E. (2006). How to design and evaluate research in education. New York: Mc Graw-Hill.

Gerold, R. A., \& Barnes, D. R. (1986). Elementary School Level Students' Perceptions of Their School World. (ERIC Document Reproduction Service No: ED269154)

Hallinger, P., Bickman, L., \& Davis, K. (1996). School context, principal leadership, and student reading achievement. The Elementary School Journal, 96(5), 527-549.

Hetland, H., Skogstad, A., Hetland, J., \& Mikkelsen, A. (2011). Leadership and learning climate in a work setting. European Psychologist, 16, 163-173. Doi:10.1027/10169040/a000037. 
Hinkin, T. R. (1995). A review of scale development practices in the study of organizations. Journal of Management, 21(5), 967-988.

Hodkinson, H., \& Hodkinson, P. (2005). Improving schoolteachers' workplace learning. Research papers in education, 20(2), 109-131. Doi: $10.1080 / 02671520500077921$

Hollingsworth, H. (1999). Teacher professional growth: A study of primary teachers involved in mathematics professional development, Unpublished doctoral thesis, Deakin University, Burwood, Australia.

Honey, P., \& Mumford, A. (1996). How to manage your learning environment. Peter Honey, Maidenhead

Hoyle, J. R. (1972). Learning environments: Space and perceptions. College Station: Texas A\&M University. (ERIC Document Reproduction Service No: ED117815)

Hu, L.T., \& Bentler, P. M. (1995). Evaluating model fit. In R. H. Hoyle (Eds.), Structural equation modeling: Concepts, issues and applications, (pp.76-99). Thousand Oaks, CA: Sage

Johnson, D.W., \& Johnson, R.T. (1999). Learning together and alone: Cooperative, competitive, and individualistic learning (5th ed.). New York: Allyn \& Bacon.

Jöreskog, K. G., \& Sörbom, D. (1993). LISREL 8: Structural equation modeling with the simplis command language. Lincolnwood: Scientific Software International, Inc.

Kanadlı, S., \& Bağçeci, B. (2016). Öğretmenlerin kişiler arası motivasyon stilleri: Öğrenme İklimi Ölçeği’nin Türkçe versiyonu. Anadolu Üniversitesi Sosyal Bilimler Dergisi, $16(1), 1-12$.

Kaplan, L. S., \& Geoffroy, K. E. (1990). Enhancing the school climate: New opportunities for the counselor. The School Counselor, 38(1), 7-12.

Karasar, N. (1999). Bilimsel araştırma yöntemi - kavramlar, ilkeler, teknikler. Ankara: Nobel.

Kline, P. (1994). An easy guide to factor analysis. London: Routledge.

Koops B. J., \& Winsor, K. (2006). Creating a Professional Learning Culture, The Journal of Education, 186 (3), 61-70. 
Lezotte, L. W., Hathaway, D. V., Miller, S. K., Passalacqua, J., \& Brookover, W. B. (1980). School learning climate and student achievement. Tallahassee: Florida State University Foundation.

Liu, Y., Ding, C., Berkowitz, M. W., \& Bier, M. C. (2014). A psychometric evaluation of a revised school climate teacher survey. Canadian Journal of School Psychology, 29(1), 54-67. Doi. 10.1177/0829573514521777.

Liu, S., Hallinger, P., \& Feng, D. (2016). Supporting the professional learning of teachers in China: Does principal leadership make a difference?, Teaching and Teacher Education, 59 (2016), 79-91. Doi. https://doi.org/10.1016/j.tate.2016.05.023.

Lowe, J. (1990) The interface between educational facilities and learning climate in three elementary schools, Unpublished doctoral dissertation, Texas A\&M University, College Station, TX, USA.

Marsick, V. J., \& Watkins, K. E. (2003). Demonstrating the value of an organization's learning culture: the dimensions of the learning organization questionnaire. Advances in Developing Human Resources, 5(2), 132-151. Doi: $10.1177 / 1523422303005002002$.

Masitsa, M.G. (2005). The principal's role in restoring a learning culture in township secondary schools, Africa Education Review, 2(2), 205-220, Doi: $10.1080 / 18146620508566301$.

Meydan, C. H. \& Şeşen, H. (2011). Yapısal eşitlik modellemesi Amos uygulamaları. Ankara: Detay.

Mikkelsen, A., \& Grønhaug, K. (1999). Measuring organizational learning climate: A crossnational replication and instrument validation study among public sector employees. Review of public personnel administration, 19(4), 31-44. Doi. 10.1177/0734371X9901900404

Moreland, J. Y. (1984). A study of the relationships among student achievement, school learning climate, and personality types of elementary school principals, Unpublished doctoral dissertation, Georgia State University, Georgia.

Nikolova, I., Van Ruysseveldt, J., De Witte, H., \& Van Dam, K. (2014). Learning climate scale: Construction, reliability and initial validity evidence. Journal of Vocational Behavior, 85(3), 258-265. Doi. 10.1016/j.jvb.2014.07.007. 
Nunnally, J. C. (1978). Psychometric theory (2nd ed.). New York: McGraw-Hill.

O'Donnell, R. J., \& White, G. P. (2005). Within the accountability era: Principals' instructional leadership behaviors and student achievement. NASSP Bulletin, 89(645), 56-71.

Opfer, V. D., Pedder, D. J., \& Lavicza, Z. (2011). The influence of school orientation to learning on teachers' professional learning change. School Effectiveness and School Improvement, 22(2), 193-214. Doi.10.1080/09243453.2011.572078.

Oluremi, O. (2008), Principals' leadership behavior and school learning culture in Ekiti state secondary schools, The Journal of International Social Research, 1(3), 301-311.

Öğdem, Z. (2015). Mesleki öğrenme topluluğu olarak ilköğretim okullarında takım liderliği ve örgüt iklimi, Yayımlanmamış doktora tezi, Gazi Üniversitesi, Ankara.

Pan, Y. H. (2014). Relationships among teachers' self-efficacy and students' motivation, atmosphere, and satisfaction in physical education. Journal of Teaching in Physical Education, 33(1), 68-92. Doi. 10.1123/jtpe.2013-0069.

Perry, N. E., \& Rahim, A. (2011). Studying self-regulated learning in classrooms. In B. J. Zimmerman \& D. H. Schunk (Eds.), Handbook of self-regulation of learning and performance (pp. 122-136). New York, NY: Taylor \& Francis.

Prieto, I.M., \& Revilla, E. (2006). Formal and informal facilitators of learning capability: the moderating effect of learning climate. IE Working Paper.

Resendiz, B. (1994). Comparison of school learning in selected chapter I and non- chapter I schools in the northside independent school district, Unpublished doctoral dissertation, Texas A \& M University, Texas.

Rousseau, D. M. (1988). The construction of climate in organizational research. International Review of Industrial and Organizational Psychology, 10, 139-146.

Schein, E. H. (1990). Organizational culture. American Psychologist, 45, 109-119.

Schermelleh-Engel, K., Moosbrugger, H. \& Müller, H. (2003). Evaluating the fit of structural equation models: Test of significance and descriptive goodness-of-fit measures. Methods of Psychological Research-Online, 8(2), 23-74.

Schunk, D. H., \& Pajares, F. (2009). Self-efficacy theory. In K. R. Wentzel, \& A. Wigfield (Eds.), Handbook of motivation at school (pp. 49-68). Routledge. 
Shoshani, A. \& Eldor, L. (2016). The informal learning of teachers: Learning climate, job satisfaction and teachers' and students' motivation and well-being. International Journal of Educational Research, 79, 52-63. Doi. 10.1016/j.ijer.2016.06.007

Schumacker, R. E., \& Lomax, R. G. (2004) A beginner's guide to structural equation modeling. New Jersey. Lawrence Erlbaum Associates.

Silins, H. C., Mulford, W. R., \& Zarins, S. (2002). Organizational learning and school change. Educational Administration Quarterly, 38(5), 613-642. Stoll, L. (2009). Capacity building for school improvement or creating capacity for learning? A changing landscape. Journal of Educational Change, 10(2-3), 115-127.

Sung, S. Y., \& Choi, J. N. (2014). Do organizations spend wisely on employees? Effects of training and development investments on learning and innovation in organizations. Journal of Organizational Behavior, 35(3), 393-412. Doi. 10.1002/job.1897.

Sümer, N. (2000). Yapısal eşitlik modelleri: Temel kavramlar ve örnek uygulamalar. Türk Psikoloji Yazılarl, 3(6), 49-74.

Sweetland, S. R., \& Hoy, W. K. (2000). School characteristics and educational outcomes: Toward an organizational model of student achievement in middle schools. Educational Administration Quarterly, 36(5), 703-729. Doi. 10.1177/00131610021969173.

Şencan, H. (2005). Sosyal ve davranışsal ölçümlerde güvenirlik ve geçerlilik. Ankara: Seçkin Yayıncılık.

Şentürk, H. E., \& Mutlu, T. O. (2019). An investigation on learning climate at sport high schools. Journal of Education and Training Studies, 7(9), 90-96.

Şişman, M. (2011). Eğitimde mükemmellik arayışı: Etkili okullar. Ankara. Pegem Akademi

Tabachnick, B. G. \& Fidell, L. S. (2007). Using multivariate statistics. Boston: Pearson.

Tavşancıl, E (2006). Tutumların ölçülmesi ve SPSS ile veri analizi. Ankara: Nobel Yayın

Tezbaşaran, A. (2008). Likert tipi ölçek hazırlama kılavuzu. Üçüncü Sürüm E-Kitap. [https://www.academia.edu/1288035/Likert_Tipi_Ölçek_Hazırlama_Kılavuzu], Erişim tarihi: 20.05.2020.

Vermeulen, M., Kreijns, K., Van Buuren, H., \& Van Acker, F. (2017). The role of transformative leadership, ICT-infrastructure and learning climate in teachers' use 

technology, 48(6), 1427-1440. Doi.10.1111/bjet.12478.

Villegas-Reimers, E. (2003). Teacher professional development: An international review of the literature. UNESCO: International Institute for Education Planning, Paris.

Wang, M. L. (2012). How does the learning climate affect customer satisfaction? The Service Industries Journal, 32(8), 1283-1303.

Wang, M. T., \& Degol, J. L. (2016). School climate: A review of the construct, measurement, and impact on student outcomes. Educational Psychology Review, 28(2), 315-352.

Yıldırım, A., \& Şimşek, H. (2008). Sosyal bilimlerde nitel araştırma yöntemleri. Ankara: Seçkin.

Yielding, A. C. (1993). Interface between educational facilities and learning climate in three northern Alabama K-2 elementary schools, Unpublished doctoral dissertation, University of Alabama.

Yurdugül, H. (2005). Ölçek geliştirme çalışmalarında kapsam geçerliği için kapsam geçerlik indekslerinin kullanılması. XIV Ulusal Ĕ̆itim Bilimleri Kongresi Pamukkale, 1, 771-774. 